\title{
A Rating-Based Sovereign Credit Risk Model: Theory and Evidence*
}

\author{
Haitao $\mathrm{Li}_{,}^{\dagger} \quad \mathrm{Tao} \mathrm{Li}_{,}^{\ddagger} \quad$ and Xuewei Yang ${ }^{\S}$
}

January 6, 2014

\begin{abstract}
We develop a rating-based continuous-time model of sovereign credit risk with closed-form solutions for a wide range of credit derivatives. In our model, rating transition follows a continuoustime Markov chain, and countries with same credit rating share similar level of default risk. A parsimonious version of our model, with only 16 parameters, one common and one country-specific factor, can simultaneously capture the term structure of CDS spreads of 34 in-sample and 34 outof-sample countries well. On average, the common factor explains more than $60 \%$ of the variations of the CDS spreads of both the in-sample and out-of-sample countries, and $80 \%$ of the variations of the common factor is explained by the CBOE VIX index, the 5-year US Treasury rate, and the CDX NA IG Index.
\end{abstract}

Keywords: Credit Rating, Sovereign Credit Risk, Credit Default Swap, Systematic Risk JEL Classification: G22, G33

\footnotetext{
*We thank Stephen Figlewski, Masaaki Kijima, and seminar participants at Kyoto University, Nanjing University, Shanghai Finance University, the University of Tokyo, the PKU-Tsinghua-Stanford Joint Conference in Quantitative Finance, and the 2014 Econometric Society Winter Meeting for helpful comments and suggestions. We are responsible for any remaining errors.

${ }^{\dagger}$ Cheung Kong Graduate School of Business, Beijing 100738, China, email: htli@ckgsb.edu.cn.

‡Department of Economics and Finance, City University of Hong Kong, Kowloon, Hong Kong, email: taoli96@gmail.com. §School of Management and Engineering, Nanjing University, Nanjing 210093, China, email: xwyang@nju.edu.cn.
} 


\title{
A Rating-Based Sovereign Credit Risk Model: Theory and Evidence
}

\begin{abstract}
We develop a rating-based continuous-time model of sovereign credit risk with closed-form solutions for a wide range of credit derivatives. In our model, rating transition follows a continuoustime Markov chain, and countries with the same credit rating share a similar level of default risk. A parsimonious version of our model, with only 16 parameters, as well as one common and one country-specific factor, can simultaneously capture the term structure of CDS spreads of 34 insample and 34 out-of-sample countries well. On average, the common factor explains more than $60 \%$ of the variations of the CDS spreads of both the in-sample and out-of-sample countries, and $80 \%$ of the variations of the common factor is explained by the CBOE VIX index, the 5-year US Treasury rate, and the CDX NA IG Index.
\end{abstract}

Keywords: Credit Rating, Sovereign Credit Risk, Credit Default Swap, Systematic Risk JEL Classification: G22, G33 
“... we live again in a two-superpower world. There is the US and there is Moody's. The US can destroy a country by leveling it with bombs; Moody's can destroy a country by downgrading its bonds."

Thomas L. Friedman, The New $\mathfrak{Y} o r k \mathfrak{T} \mathfrak{T} \mathfrak{i m e s}$, Feb 22, 1995

\section{Introduction}

The Eurozone debt crisis has highlighted the importance of sovereign credit risk in global financial markets. It has also brought back memories of the huge losses that investors in sovereign debts have suffered in many similar crises in the past two centuries, such as the "Baring Crisis" of the 1890s, the Latin American debt crisis of the 1980s, and the Mexican and Russian debt crisis of the 1990s. A large literature has been developed in economics and finance to understand the nature, causes, and consequences of sovereign debt crisis as well as the pricing and management of sovereign credit risk. Extensive research over the past decades has revealed important patterns in both the cross-sectional and time series variations of sovereign credit spreads.

One line of research has focused on the role of credit rating in sovereign credit markets. ${ }^{1}$ By grouping borrowers into broad categories with similar credit qualities, credit rating provides a first-order approximation of the level of default risk. Numerous studies, such as Cantor and Packer (1996) , have shown that sovereign credit rating reflects the macroeconomic fundamentals of a country and that there are significant variations in sovereign credit spreads across different rating classes. Moreover, rating transition represents a discrete and material change in the credit quality of a borrower. During the recent global financial crisis, downgrades of sovereign governments (from the PIIGS countries in Europe to the strongest borrower in the world, the US government) by credit rating agencies have resulted in violent reactions in the sovereign CDS market. Several recent event studies have empirically documented the significant impacts of rating changes on sovereign CDS spreads for both developed and emerging market countries. ${ }^{2}$ However, this strand of literature does not explicitly model the dy-

\footnotetext{
${ }^{1}$ There is a huge literature on the impact of credit rating agencies for both corporate and sovereign credit markets. For brevity, we refer readers to Kiff et al. (2012) for a partial review of the literature on sovereign credit rating.

${ }^{2}$ For example, based on rating changes and CDS spreads of 22 emerging market countries between 2001 and 2008 , Ismailescu and Kazemi (2010) document the direct effects of announcements of sovereign rating changes on CDS spreads of the event countries and the spillover effects on other emerging market countries. Afonso et al. (2012) show that for a large
} 
namic evolution of sovereign credit risk.

Another line of research, based on the reduced-form approach of Duffie and Singleton (1999 and 2003), has shown that time series fluctuations of sovereign credit spreads are mostly driven by common risk factors. For example, Pan and Singleton (2008) show that one common principal component (PC) explains more than $90 \%$ of the variations of the CDS spreads of three geographically dispersed countries: Mexico, Turkey, and Korea. Longstaff et al. (2011) conclude that the CDS spreads of 26 developed and emerging market countries are driven primarily by the VIX index, US equity, and highyield factors. Based on a sovereign credit risk model with a common and a country-specific factor, Ang and Longstaff (2013) show that the US and European systemic factors extracted from the CDS spreads of the US government, 10 individual US states, and 11 EMU sovereigns are highly correlated with one another and are strongly related to financial market variables.

In this paper, inspired by the two lines of research, we develop a rating-based continuous-time model for sovereign credit risk that explicitly incorporates the well-known cross-sectional and time series properties of sovereign credit spreads and provides closed-form solutions for a wide range of credit derivatives. ${ }^{3}$ In our model, the credit rating of each country follows a continuous-time Markov chain characterized by a common transition matrix, and countries within a given rating category share similar default intensity. Following Ang and Longstaff (2013), we assume that the default risk of a sovereign borrower is driven by a common and a country-specific factor. The common factor drives the rating transition matrix as well as the systematic component of default risk, and the default intensities of countries in different rating categories have different loadings on the common factor. The countryspecific factor captures the idiosyncratic component of the default risk of each individual country. ${ }^{4}$ The number of parameters of our model does not increase with the number of countries, given that

group of European countries, the reactions of CDS spreads to negative rating events have increased since the Lehman Brothers bankruptcy on September 15, 2008. They also report spillover effects of rating announcements, particularly from lower rated countries to higher rated ones.

${ }^{3}$ While a series of studies, such as Jarrow et al. (1997), Lando (1998), Kijima (1998), Das and Hanouna (1996), Arvanitis et al. (1999), Huge and Lando (1999), and Li (2000), have considered credit rating for the pricing of corporate default risk, our model is one of the first rating-based models in the literature on sovereign credit risk.

${ }^{4}$ Ang and Longstaff (2013) use Germany as the systemic factor for European countries and US for individual states. This modeling choice is perfectly sensible given the purpose of their research. Given that we want to price CDS spreads of countries from different parts of the world, such as Europe, North and Latin America, Asia, and Middle East, we allow each country to have its own country-specific factor in our model. 
countries share the same set of parameters for the country-specific factor.

One of the most appealing features of our rating-based approach is that by explicitly modeling the cross-sectional and time series properties of sovereign credit spreads, it can simultaneously capture the credit spreads of multiple countries under a parsimonious and unified modeling framework. Given the strong dependence of sovereign credit spreads on credit rating, incorporating rating information into the existing reduced-form models significantly enhance these models' capability to capture the crosssectional variations of sovereign credit spreads. Therefore, while the existing reduced-form models mostly focus on pricing the credit risk of individual countries, the ultimate goal of our rating-based model is to capture the credit spreads of all countries, which makes it possible to analyze the default risk of portfolios of sovereign credit instruments.

Another important advantage of our rating-based model is that it naturally captures both continuous evolution and discrete change in the default risk of a sovereign borrower due to rating transition. Existing reduced-form models, which assume that the default intensity of a sovereign borrower follows a continuous diffusion process, would have difficulty in capturing the dramatic increases in the default risk of sovereign borrowers due to rating downgrades. Historically, a highly rated borrower rarely defaults immediately. Instead, it is more likely to be downgraded first before defaults. Therefore, the credit risk of a sovereign borrower consists of the risk of default as well as the risk of downgrading. Moreover, rating downgrades (particularly from investment grade to non-investment grade) could seriously affect the market's perception of the credit quality of a borrower and thus limit its access to capital markets. Therefore, incorporating rating information into existing reduced-form sovereign credit risk models could help to capture the default risk of sovereign borrowers more completely and yield better insights about the sovereign credit market. ${ }^{5}$

By incorporating fundamental information (summarized in credit ratings) into existing reducedform models, our model avoids overfitting the data and improves the efficiency of model estimation. While existing reduced-form models choose latent default factors to match the observed credit spreads

\footnotetext{
${ }^{5}$ Our paper is most closely related to Farnsworth and Li (2007) and Remolona et al. (2008). While Farnsworth and Li (2007) develop a rating-based model for corporate credit risk, our paper is one of the first that studies the effect of rating on the pricing of sovereign CDS spreads in a dynamic setting.
} 
of individual countries, our approach requires countries with similar credit ratings to share similar level of default risk. As a result, pricing errors under our model reflect inconsistencies between observed credit spreads and underlying credit rating and therefore could be strong signs of future rating changes. Since countries with the same credit rating share similar level of default risk, our approach uses the credit spreads of all countries jointly to estimate the model and significantly increase the estimation efficiency of the common default factor. This case is similar to the portfolio approach in the equity literature, which estimates asset pricing models using portfolios of securities with similar risk exposures instead of individual securities.

Consistent with our objective, we apply our parsimonious model with only 16 parameters, one common and one country-specific factor, to capture the term structure of CDS spreads of 68 countries between January 2004 and March 2012. The ratings of these countries are obtained from Standard \& Poor's and are grouped into 7 broad rating categories: AAA, AA, A, BBB, BB, B, and CCC. While existing models for sovereign credit risk are typically estimated country by country, we estimate our rating-based model simultaneously using the term structure of CDS spreads of the 34 in-sample countries, which have the most observations via maximum likelihood. We then use the estimated model to price the CDS spreads of the 34 out-of-sample countries, which have fewer observations. We choose the common factor to match the average CDS spreads of the in-sample countries across all maturities and use it to price the out-of-sample countries. We choose the country-specific factor to match the average CDS spreads of each in-sample and out-of-sample country over all maturities given the common factor.

Overall, our rating-based model can capture the term structure of CDS spreads of the 34 in-sample countries reasonably well. The model has small average absolute pricing errors relative to the average bid-ask spreads of the CDS spreads, particularly for intermediate maturities and ratings. Notably, our extremely parsimonious model has equally good or even better pricing performance for the 34 out-ofsample countries. For a wide range of out-of-sample countries, the average absolute pricing errors at intermediate maturities ( 2 to 7 years) are lower or at par with the average bid-ask spreads.

Although we find relatively large pricing errors for certain countries during certain parts of our 
sample period, in almost all cases, the pricing errors reflect inaccuracies in the credit ratings of these countries. For example, in 2004 and 2005, our model has large pricing errors for some Latin American countries, such as Brazil and Colombia. News reports during this time suggest that market participants believe that these countries are underrated and their ratings do not fully reflect the improved macroeconomic fundamentals due to rising exports, declining deficits, and strengthening local currencies. The large pricing errors disappear as the countries are gradually upgraded. We also find relatively large pricing errors for some of the Eurozone countries during the 2008 global financial crisis and the 2011 European debt crisis. The unstable ratings of these countries, as evidenced by their subsequent credit downgrades and negative watches, significantly affect their CDS spreads.

Given the important role played by the common factor for sovereign CDS pricing, we examine the nature of the common factor from several different perspectives. We first show that our model with the common factor alone, i.e., setting all country-specific factors to be zero, can explain more than 60\% of the variations of the CDS spreads of the 34 in-sample and 34 out-of-sample countries on average. Therefore, by simply adding a cross-sectional dimension to existing reduced-form models with only the common factor, we obtain an extremely parsimonious model that can capture the majority of the variations of the CDS spreads of most countries. Since we do not have a country-specific factor, the 34 out-of-sample countries are purely out of sample. As a result, we expect the model to work equally well for additional out-of-sample countries.

Following existing studies, we then explore the economic forces that drive the common factor, the market price of default risk, and the credit risk premium. The common factor extracted from our model can explain a large fraction of the CDS spreads of most countries and has close connections to financial market variables. For example, we find that the VIX index, the 5-year constant maturity Treasury rates, and the CDX NA IG can explain more than $80 \%$ of the variations of the common factor, the market price of risk, and the credit risk premium. We also find that the credit risk premium increases dramatically during the global financial crisis and the European debt crisis. This is especially more pronounced for CDS with higher ratings and longer maturities.

The rest of the paper is organized as follows. In Section 2, we develop a general rating-based 
continuous-time model for sovereign credit risk. We discuss the data used in our empirical study and the estimation method in Section 3 and report the empirical results in Section 4. Section 5 concludes the paper.

\section{A Rating-Based Sovereign Credit Risk Model}

In this section, we first introduce a general rating-based continuous-time model for sovereign credit risk. We then consider a special version of the model with one common and one country-specific factor with closed-form solutions for a wide range credit derivatives. Finally, we consider a multifactor extension of the baseline model. Throughout the analysis, we assume there exists a risk-neutral probability space $(\Omega, \mathcal{F}, \mathbf{F}, \mathcal{Q})$, under which all securities can be priced appropriately. All expectations are taken under this risk-neutral probability measure $\mathcal{Q}$.

\subsection{A General Model with Credit Ratings}

Suppose all sovereign borrowers can be classified into $K$ possible credit rating categories and the rating for each country follows a continuous-time Markov chain characterized by a common transition matrix

$$
Q(t)=\left\{q_{i j}(t)\right\}_{\{i, j=1, \ldots, K\}}
$$

where $\sum_{j=1}^{K} q_{i j}=0$. Intuitively, over a short horizon $\Delta t$, the probability for a rating change from $i$ to $j \neq i$ is $q_{i j} \Delta t$.

Following Farnsworth and Li (2007) or Li (2000), we also assume that countries in the same rating category share the same default intensity. That is, if a country is rated

$$
C R(t) \in\{1, \cdots, K\}
$$

then its hazard rate of default is $h_{C R(t-)}(t)$. Let $H$ be a diagonal matrix with its diagonal element $H_{i i}=h_{i}(t)$, which represents the default intensity of a country with a rating $i$. Let $P(t, T)$ be the price 
vector associated with a payoff $P(T)$ at maturity $T$, our goal is to derive a pricing equation for $P(t, T){ }^{6}$ Let $C R(t-)=i$ and applying Itô's Lemma to $P_{C R(t)}(t, T)$ yields

$$
E_{t}\left[d P_{C R(t)}(t, T)\right]=E_{t}\left[d P_{i}(t, T)\right]+\sum_{k=1}^{K} q_{i k}\left(P_{k}(t, T)-P_{i}(t, T)\right) d t+h_{i}(t)\left(P_{i}^{D}(t)-P_{i}(t, T)\right) d t
$$

where $P_{i}^{D}$ is the payoff at default. As no-arbitrage requires $E_{t}\left[d P_{C R(t)}(t, T)\right]=r(t) P_{C R(t-)}(t, T) d t$, we have

$$
E_{t}\left[d P_{i}(t, T)\right]+\sum_{k=1}^{K} q_{i k}\left(P_{k}(t, T)-P_{i}(t, T)\right) d t+h_{i}(t)\left(P_{i}^{D}(t)-P_{i}(t, T)\right) d t=r(t) P_{i}(t, T) d t
$$

where $r$ is the risk-free interest rate. By the fact that $\sum_{k=1}^{K} q_{i k}=0$, we can rewrite the equation in terms of vectors and matrices as

$$
E_{t}[d P(t, T)]=[r(t) I+H(t)] P(t, T) d t-Q(t) P(t, T) d t-H(t) P^{D}(t) d t
$$

where $Q, H$, and $P^{D}$ are some suitable measurable stochastic processes.

It can be shown that pricing equation (1) is equivalent to

$$
\begin{aligned}
P(t, T)=E_{t}\left[\exp \left(-\int_{t}^{T} r(s) d s\right) \Phi(t, T) P(T)\right. \\
\left.\quad+\int_{t}^{T} \exp \left(-\int_{t}^{s} r(a) d a\right) \Phi(t, s) H(s) P^{D}(s) d s\right],
\end{aligned}
$$

where $\Phi(t, s)$ is defined as the solution to the following ordinary differential equation

$$
\frac{d \Phi(t, s)}{d t}=-[Q(t)-H(t)] \Phi(t, s)
$$

with boundary condition $\Phi(s, s)=I$.

Pricing equation (2) has a natural and intuitive interpretation. $\Phi(t, s)$ is the probability matrix that

\footnotetext{
${ }^{6}$ For a coupon bond, $P(T)=1$. The model can easily price credit linked notes by setting appropriate rating-dependent terminal payoff $P(T)$.
} 
the security has not defaulted up to time $s, H(s) d s$ is the default probability matrix over $d s, P^{D}(s)$ is the cash flow vector when the security defaults, and $P(T)$ is the cash flow vector if the security does not default up to $T$. Thus, the summation (integration) over all of the expected discounted cash flows under the risk-neutral probability yields the price of the security.

A single-name CDS buyer pays a constant premium $c$ in exchange for a one-time cash flow $\mathbf{1}$ $P^{D}(s)=L(s) \mathbf{1}$ when a reference defaultable bond defaults at date $s$. The protection buyer also stops paying any remaining premium after default. To compute the value of the premium (fixed) leg of a CDS contract, we simply substitute $P(T)=c \Delta t \mathbf{1}$ and $P^{D}(s)=0$ in equation (2) for $T=T_{m}, m=$ $1, \cdots, M .^{7}$ Thus, the value of the fixed leg is $c P_{f x}(t, T)$, where

$$
P_{f x}(t, T)=\Delta t \sum_{m=1}^{M} E_{t}\left[\exp \left(-\int_{t}^{T_{m}} r(s) d s\right) \Phi\left(t, T_{m}\right)\right] \mathbf{1},
$$

$\Delta t=T_{m+1}-T_{m}$, and $T_{M}=T$.

For the default (floating) leg, substituting $P(T)=0$ and $P^{D}(s)=L(s) \mathbf{1}$ into equation (1) yields the value of the floating leg:

$$
P_{f l}(t, T)=E_{t}\left[\int_{t}^{T} \exp \left(-\int_{t}^{s} r(a) d a\right) \Phi(t, s) H(s) L(s) d s\right] \mathbf{1}
$$

If the reference bond is rated $i$, then the premium $c$ is given by

$$
\operatorname{CDS}_{i}(t, T)=\frac{\mathbf{1}_{i}^{\top} P_{f l}(t, T)}{\mathbf{1}_{i}^{\top} P_{f x}(t, T)}
$$

where $\mathbf{1}_{i}$ is a vector of zeros except that its $i$ th element equals 1.

\footnotetext{
${ }^{7}$ Accruals can be easily accounted by setting $P^{D}(s)=\left(s-n_{s} \Delta t\right) \mathbf{1}$, where $n_{s}$ is the greatest integer smaller than $s / \Delta t$. In this case we have

$$
\begin{aligned}
P_{f x}(t, T)=\Delta t \sum_{m=1}^{M} E_{t}[\exp & \left.\left(-\int_{t}^{T_{m}} r(s) d s\right) \Phi\left(t, T_{m}\right)\right] \mathbf{1} \\
& +E_{t}\left[\int_{t}^{T} \exp \left(-\int_{t}^{s} r(a) d a\right) \Phi(t, s) H(s)\left(s-n_{s} \Delta t\right) d s\right] \mathbf{1} .
\end{aligned}
$$
}

The extra term is similar to the valuation of the floating leg of a CDS. 


\subsection{A Model with One Common and One Country-Specific Factor}

In this section, we develop a special version of our model with one common factor $z$, which affects the rating transition matrix and the sovereign default risk of all countries, and one country-specific factor $y$, which captures the idiosyncratic component of the default risk of individual countries. In particular, we have

$$
Q(t)=\bar{Q}\left(\alpha+z_{t}\right), \quad H(t)=\bar{H}\left(\alpha+z_{t}\right)+I y_{t},
$$

where $\bar{Q}$ is a constant transition matrix, and $\bar{H}$ is constant diagonal matrix. These assumptions imply that the common factor $z$ affects both the default risk across credit ratings and the transition of credit ratings. When $z$ increases, the overall default risk increases, and credit ratings become less stable. The country-specific factor $y$ only affects the default risk of a specific country and has no effect on the transition matrix of credit ratings.

We assume that the common factor $z$ follows a CIR process under the risk-neutral measure

$$
d z_{t}=\kappa\left(\theta-z_{t}\right) d t+\sigma \sqrt{z_{t}} d W_{t}
$$

where $W_{t}$ is a Brownian motion, $\kappa, \theta$, and $\sigma$ are positive constants. ${ }^{8}$ We assume the price of risk for the common factor has the following form

$$
\lambda(t)=\frac{1}{\sigma \sqrt{z_{t}}}\left(\lambda+\lambda_{z} z_{t}\right)
$$

Thus, the dynamics of $z_{t}$ under the physical measure is

$$
d z_{t}=\kappa^{P}\left(\theta^{P}-z_{t}\right) d t+\sigma \sqrt{z_{t}} d W_{t}^{P}
$$

where $W_{t}^{P}$ is the Brownian motion under the physical measure, and

$$
\kappa^{P}=\kappa-\lambda_{z}, \quad \theta^{P}=(\kappa \theta+\lambda) / \kappa^{P} .
$$

\footnotetext{
${ }^{8}$ In general, $z_{t}$ could also be a linear function of several processes as that in the affine term structure models.
} 
Given this physical dynamics, it is straightforward to derive the transition probability and the likelihood of the systematic factor.

The country-specific factor $y$, which carries no risk premium, follows a Vasicek process

$$
d y_{t}=\kappa_{y}\left[\theta_{y}-y_{t}\right] d t+\sigma_{y} d W_{t}^{y}
$$

where $W^{y}$ is independent of $W$.

There are different ways to model the loss at default process L. Although we could allow each country to have its own loss at default or countries in the same rating category to share the same level of loss of default, for convenience, we assume that all countries share the same level of loss of default. We also assume that the risk-free interest rate $r$ is independent of $z .^{9}$ This independence assumption enables us to separate the expectations between the risk-free rate and default risk components, thus simplifying the computation of CDS spreads.

\subsubsection{Common Factor}

The key to compute the pricing formulae (4) and (5) is to compute the following expectations:

$$
E_{t}[\Phi(t, T)] \text { and } E_{t}[\Phi(t, T) H(t)]
$$

Given the affine structure of our model, $\Phi$ has a closed-form solution as follows:

$$
\Phi(t, T)=\Omega \exp \left(\Lambda \int_{t}^{T}\left(\alpha+z_{a}\right) d a\right) \Omega^{-1}
$$

where $\Omega \Lambda \Omega^{-1}=\bar{Q}-\bar{H}$, and $\Lambda$ is a diagonal matrix with its elements as eigenvalues of $\bar{Q}-\bar{H}$. Since $\Lambda$ is a diagonal matrix, we have that

$$
\exp \left(\Lambda \int_{t}^{s}\left(\alpha+z_{a}\right) d a\right)
$$

\footnotetext{
${ }^{9}$ This independence assumption can be relaxed through a linear relation between $r$ and $z$, such as $r(s)=X(s)+\rho z_{t}$, where $X$ and $z$ are independent, and $X$ represents other factors that affect the default-free term structure.
} 
is also a diagonal matrix with its diagonal element $i$

$$
\exp \left(\Lambda_{i i} \int_{t}^{s}\left(\alpha+z_{a}\right) d a\right)
$$

It is straightforward to show that

$$
E_{t}[\Phi(t, s)]=\Omega \Gamma^{1}\left(\tau, z_{t}\right) \Omega^{-1},
$$

where $\tau=s-t$, and $\Gamma^{1}$ is a diagonal matrix with its diagonal elements equal to

$$
\Gamma_{i i}^{1}\left(\tau, z_{t}\right)=p_{0}\left(\tau, \alpha \Lambda_{i i}\right) p_{1}\left(\tau, z_{t}, \Lambda_{i i}\right)
$$

We can also show that

$$
E_{t}[\Phi(t, s) H(s)]=\Omega \Gamma^{2}\left(\tau, z_{t}\right) \Omega^{-1} \bar{H}
$$

where $\Gamma^{2}$ is a diagonal matrix with its diagonal elements equal to

$$
\begin{gathered}
\Gamma_{i i}^{2}\left(\tau, z_{t}\right)=p_{0}\left(\tau, \alpha \Lambda_{i i}\right)\left[\alpha p_{1}\left(\tau, z_{t}, \Lambda_{i i}\right)+p_{2}\left(\tau, z_{t}, \Lambda_{i i}\right)\right] \\
p_{0}(\tau, \beta)=\exp (\beta \tau), \\
p_{1}\left(\tau, z_{t}, \beta\right)=E_{t}\left[\exp \left(\beta \int_{t}^{s} z_{a} d a\right)\right]=A(\beta, \tau) e^{B(\beta, \tau) z_{t}}, \\
p_{2}\left(\tau, z_{t}, \beta\right)=E_{t}\left[z_{s} \exp \left(\beta \int_{t}^{s} z_{a} d a\right)\right]=\left[C(\beta, \tau)+D(\beta, \tau) z_{t}\right] e^{B(\beta, \tau) z_{t}},
\end{gathered}
$$

for any $\beta$, and

$$
\begin{aligned}
& A(\beta, \tau)=\exp \left(\frac{\kappa \theta(\phi+\kappa)}{\sigma^{2}} \tau\right)\left(\frac{1-\gamma}{1-\gamma e^{\phi \tau}}\right)^{\frac{2 \kappa \theta}{\sigma^{2}}} \\
& B(\beta, \tau)=\frac{\kappa-\phi}{\sigma^{2}}+\frac{2 \phi}{\sigma^{2}\left(1-\gamma e^{\phi \tau}\right)}
\end{aligned}
$$




$$
\begin{aligned}
C(\beta, \tau) & =\frac{\kappa \theta}{\phi}\left(e^{\phi \tau}-1\right) \exp \left(\frac{\kappa \theta(\phi+\kappa)}{\sigma^{2}} \tau\right)\left(\frac{1-\gamma}{1-\gamma e^{\phi \tau}}\right)^{\frac{2 \kappa \theta}{\sigma^{2}}+1}, \\
D(\beta, \tau) & =\exp \left(\frac{\kappa \theta(\phi+\kappa)+\phi \sigma^{2}}{\sigma^{2}} \tau\right)\left(\frac{1-\gamma}{1-\gamma e^{\phi \tau}}\right)^{\frac{2 \kappa \theta}{\sigma^{2}}+2}, \\
\phi & =\sqrt{-2 \beta \sigma^{2}+\kappa^{2}}, \quad \gamma=\frac{\kappa+\phi}{\kappa-\phi}
\end{aligned}
$$

Thus, it is straightforward to obtain the value of the fixed leg via equation (4). A numerical integration is needed to compute (5) for the floating leg as follows:

$$
P_{f l}(t, T)=\Omega\left[\int_{t}^{T} P_{0}(t, s) \Gamma^{2}\left(s-t, z_{t}\right) d s\right] \Omega^{-1} \bar{H} L \mathbf{1}
$$

where $P_{0}(t, s)$ is the price of default-free zero coupon bonds.

\subsubsection{Country-Specific Factor}

With the addition of the country-specific factor $y$, equations (11) and (12) become

$$
E_{t}[\Phi(t, s)]=\hat{p}_{1}\left(\tau, y_{t}\right) \Omega \Gamma^{1}\left(\tau, z_{t}\right) \Omega^{-1}
$$

and

$$
E_{t}[\Phi(t, s) H(s)]=\Omega\left[\hat{p}_{1}\left(\tau, y_{t}\right) \Gamma^{2}\left(\tau, z_{t}\right)+\hat{p}_{2}\left(\tau, y_{t}\right) \Gamma^{1}\left(\tau, z_{t}\right)\right] \Omega^{-1} \bar{H},
$$

where $\Gamma^{1}$ and $\Gamma^{2}$ are the same as defined previously, and $\hat{p}_{k}$-s are given by (see, e.g., Jamshidian, 1989)

$$
\begin{aligned}
& \hat{p}_{1}\left(\tau, y_{t}\right)=E_{t}\left[\exp \left(-\int_{t}^{s} y_{a} d a\right)\right]=\hat{A}(\tau) e^{-\hat{B}(\tau) y_{t}}, \\
& \hat{p}_{2}\left(\tau, y_{t}\right)=E_{t}\left[y_{s} \exp \left(-\int_{t}^{s} y_{a} d a\right)\right]=\left[\hat{C}(\tau)+\hat{D}(\tau) y_{t}\right] e^{-\hat{B}_{\tau} y_{t}},
\end{aligned}
$$

where $\tau=s-t$, and

$$
\hat{A}(\tau)=\exp \left(\left(\theta_{y}-\frac{\sigma_{y}^{2}}{2 \kappa_{y}^{2}}\right)(\hat{B}(\tau)-\tau)-\frac{\sigma_{y}^{2} \hat{B}^{2}(\tau)}{4 \kappa_{y}}\right)
$$




$$
\hat{B}(\tau)=\frac{1-e^{-\kappa_{y} \tau}}{\kappa_{y}}, \quad \hat{C}(\tau)=\left(\kappa_{y} \theta_{y} \hat{B}(\tau)-\frac{\sigma_{y}^{2} \hat{B}^{2}(\tau)}{2}\right) \hat{A}(\tau), \quad \hat{D}(\tau)=e^{-\kappa_{y} \tau} \hat{A}(\tau)
$$

Substituting these formulae in conjunction with the default-free term structure

$$
P_{0}(t, s)=E_{t}\left[\exp \left(-\int_{t}^{s} r_{a} d a\right)\right]
$$

in equations (4), (5), and (6) yields the CDS spreads.

\subsection{A Multi-Factor Extension}

The model with one common and one country-specific factor can be easily extended to have multiple common and country-specific factors. The common factors can be modeled as follows:

$$
Q(t)=\bar{Q}\left[\alpha_{0}+\alpha^{\top} z_{t}\right], \quad H(t)=\bar{H}\left[\alpha_{0}+\alpha^{\top} z_{t}\right]
$$

where $\bar{Q}$ is a constant transition matrix, $\bar{H}$ is a constant diagonal matrix, and $z$ is an $k \times 1$ vector with $k$ th element $z^{k}$ satisfies

$$
d z_{t}^{k}=\kappa_{k}\left[\theta_{k}-z_{t}^{k}\right] d t+\sigma_{k} \sqrt{z_{t}^{k}} d W_{t}^{k}
$$

where $W_{t}^{k}$ is independent across $k$. In this case, we only need to redefine $\Gamma$ as

$$
\Gamma_{i i}^{1}\left(\tau, z_{t}\right)=p_{0}\left(\tau, \alpha_{0} \Lambda_{i i}\right) \prod_{k=1} p_{1}\left(\tau, z_{t}^{k}, \alpha_{k} \Lambda_{i i}\right)
$$

and

$$
\Gamma_{i i}^{2}\left(\tau, z_{t}\right)=p_{0}\left(\tau, \alpha_{0} \Lambda_{i i}\right) \sum_{n=0} \alpha_{n} p_{2}\left(\tau, z_{t}^{n}, \alpha_{n} \Lambda_{i i}\right) \prod_{k \neq n} p_{1}\left(\tau, z_{t}^{k}, \alpha_{k} \Lambda_{i i}\right)
$$

where $p$ s are similar to those given by (13), except that $p_{2}\left(\cdot, z^{0}, \cdot\right)=1$. Adding one or more countryspecific factor(s) into this model is evidently straightforward. 


\section{Data and Estimation Method}

In this section, we first introduce the data used in our empirical analysis, which include the term structure of CDS spreads, the corresponding bid-ask spreads as well as the credit ratings of the 68 countries. We then discuss the estimation of our rating-based sovereign credit risk model with one common and one country-specific factor using maximum likelihood.

\subsection{Data}

We obtain the sovereign CDS spreads from Credit Market Analysis Ltd (CMA), which collects OTC market data on credit derivatives. The sample consists of monthly quotes of CDS spreads with maturities of 1, 2, 3, 5, 7, and 10 years from January 2004 to March 2012. In our analysis, we consider 68 countries $^{10}$ from North America, Europe, Asia/Pacific, Middle East, Latin America, and Africa. The discount bond prices $P_{0}(t, u)$ in the valuation formula are bootstrapped from the US Dollar LIBOR and swap rates downloaded from Bloomberg.

Table 1 provides important summary information of the 68 countries, which includes credit rating, average 5-year CDS spread, average bid-ask spread of 5-year CDS spread, number of observations, and number of rating changes for each country. The maximum number of observations for each country is 99 months. We use the top 34 countries with the most complete observations of the term structure of CDS spreads to estimate our model in sample. We then use the estimated model to price the CDS spreads of the other 34 countries with fewer observations out of sample. All the CDS spreads are denoted in basis points and quoted in US dollars. We use the Standard \& Poor's credit ratings obtained from Bloomberg. Following previous literature, we ignore minor adjustments such as "+" or "-" to baseline ratings and obtain seven broad rating categories from AAA to CCC (C and CC are merged into CCC). Ratings reported in Table 1 represent the rating of each country at the end of the sample period. ${ }^{11}$ While the ratings of 25 countries (12 in-sample and 13 out-of-sample) remain constant throughout the sample, certain countries experience up to 5 rating changes during the sample period. The average

\footnotetext{
${ }^{10}$ The original dataset covers CDS for 69 countries. We exclude Malta from our analysis, because it has observations for only six months.

${ }^{11}$ In the empirical section, we report the complete history of the evolution of the ratings of each country.
} 
5-year CDS spreads generally increase when rating deteriorates. The most common ratings are $\mathrm{A}$ and $\mathrm{BBB}$, whereas the least common one is CCC, which belongs to Greece. ${ }^{12}$ Panel A of Table 2 reports the frequency of rating changes of the 34 countries used for in-sample model estimation. In total, the 34 countries have experienced 40 rating changes (under our reclassification of ratings) during the sample period. Interestingly, rating transitions typically occur between two adjacent ratings. For example, there are 4 rating changes from A to AA. This empirical fact motivates our parametrization of the rating transition matrix as a tri-diagonal matrix in Section 3.2. The top-left panel of Figure 1 plots the numbers of quarterly rating changes and the average 5-year CDS spreads of the 34 in-sample countries. The top-right panel of Figure 1 also reports the numbers of rating downgrades during the sample period. Notably, rating changes and downgrades tend to increase when the CDS spreads widen.

Panel B of Table 2 reports the average CDS spreads for countries in different rating categories and at different maturities. Panel $\mathrm{C}$ of Table 2 also reports the average bid-ask spreads at different maturities and credit ratings. On average, we find an upward sloping term structure of CDS spreads for ratings above BB. For the CCC rating, the term structure of CDS spread is downward sloping. The CDS spreads increase monotonically when ratings worsen. The bottom two panels of Figure 1 provide time series plots of the average 5-year CDS spreads at different ratings. We see a monotonically negative relation between rating and average CDS spreads. We also see huge spikes in the CDS spreads during the global financial crisis and European debt crisis.

\subsection{Maximum Likelihood Estimation}

We use the model with one common and one country-specific factor (with $\alpha=0$ ) presented in Section 2.2 in our empirical analysis. We assume that the loss rate is $60 \%$ for all countries regardless their ratings. To reduce the parameter space, although we allow each country to have its own local factor $y_{j t}$, all countries share the same set of parameters for $y_{j}$. While the $y_{j}$ factor is supposed to capture the idiosyncratic component of a country's default risk, it might also capture small deviations from the

\footnotetext{
${ }^{12}$ After Greece's downgrade by the S\&P to Selective Default (SD) on February 27, 2012, the CDS spreads of Greece become extremely high. For example, the Greece 1-year CDS spreads were 57,166 and 57,644 basis points on February 29,2012 and March 30, 2012, respectively. Thus, we remove the last two month CDS spreads of Greece in our in-sample estimation and all subsequent analyses.
} 
average default risk for a particular sovereign credit rating due to our coarse re-classification of the observed credit ratings.

The parameters are estimated using maximum likelihood. We assume that, on each day, the sum of the CDS spreads of all countries and all maturities implied by the model with only the common factor is equal to the sum of the market CDS spreads, such that the pricing function can be inverted to obtain the common factor $z$. On each corresponding day and for each country, we assume that the sum of CDS spreads at all maturities implied by the model with both the common and country-specific factor equals that of the market quotes, such that we can back out the country specific factor $y_{j}$ given $z$. For the $j$-th country, the contract with maturity $M$ is assumed to be priced with normally distributed pricing errors with mean zero and standard error $\sigma_{j M}$.

To estimate the model, we need to compute the log-likelihood of the observed data and the model implied $z$ and $y_{j}$. Let $\epsilon_{j t}$ be the vector of pricing errors across maturites for the CDS contracts for country $j$ at time $t$, and $C R_{j}(t)$ the ratings for country $j$ at time $t$, then the likelihood function includes the following four components:

- The likelihood of the pricing error $\epsilon_{j t}$ at time $t$ given $z_{t}, y_{j t}$, and $C R_{j}(t)$, which is Gaussian by assumption, across countries;

- The likelihood of rating $C R_{j}(t)$ at time $t$ given $C R_{j}(t-\Delta), z_{t-\Delta}$, and $z_{t}$ across countries;

- The likelihood of $y_{j t}$ given $y_{j(t-\Delta)}$, which is Gaussian (see, e.g., Jamshidian, 1989), across countries;

- The likelihood of $z_{t}$ given $z_{t-\Delta}$, which is non-central $\chi^{2}$ (see, e.g., Cox et al., 1985).

Similar to that in Farnsworth and Li (2007), we assume that the transition matrix of ratings is 7by-7 tri-diagonal, such that the diagonal elements are determined by $\bar{Q}_{i, i}=-\bar{Q}_{i, i-1}-\bar{Q}_{i, i+1}$, where $\bar{Q}_{i, i-1}=\bar{Q}_{21}$ for the lower diagonal, and $\bar{Q}_{i, i+1}=\bar{Q}_{12}$ for the upper diagonal. This assumption reduces the parameter space significantly and is consistent with the frequency of rating transitions reported in 
Table 2. The transition probabilities of ratings between $t-\Delta$ and $t$ are given by

$$
\exp \left(\int_{t-\Delta}^{t} \bar{Q} z_{a} d a\right)
$$

However, since we do not have a continuous observation of $z_{a}$, we use the following to approximate the transition probabilities

$$
E^{P}\left[\exp \left(\int_{t-\Delta}^{t} \bar{Q} z_{a} d a\right) \mid z_{t-\Delta,} z_{t}\right]
$$

where the expectation is under the physical measure. ${ }^{13} \bar{H}$ is a 7-by-7 diagonal matrix. To avoid potential identification problems between $\bar{H}_{i i}$-s and the common factor $z$, we fix the value of $\bar{H}_{33}$ at 1 .

\section{Empirical Results}

In this section, we discuss the empirical results of our rating-based model for sovereign CDS pricing. We first examine the estimated parameters of the model. Then, we show that our parsimonious model with 16 parameters, one common and one country-specific factor, can price the CDS spreads of the 34 in-sample and 34 out-of-sample countries reasonably well. We also show that the relatively large pricing errors for certain countries reflect staleness of their credit ratings. Finally, we show that the common factor on average can explain more than $60 \%$ of the variations of the CDS spreads of both the in-sample and out-of-sample countries and that more than $80 \%$ of the variations of the common factor backed out from our model can be explained by the VIX index, the 5-year US Treasury rate, and the CDX NA IG index.

\subsection{Parameter Estimates}

Table 3 reports the maximum likelihood estimates of the parameters of three different versions of our rating-based model. Model $\mathrm{I}$ is the full model as described previously. All the parameter estimates of Model I are highly significant. To examine the incremental contribution of rating transition, we

\footnotetext{
${ }^{13}$ The details of the approximation can be found in the Appendix of Farnsworth and Li (2007).
} 
consider Model II, which maintains rating-dependent default intensity but does not allow transitions between different ratings. Finally, we consider Model III, which does not allow any distinctions between ratings. Likelihood ratio tests highlight the importance of credit rating in model performance and overwhelmingly reject Model III against Model II and Model II against Model I. All subsequent analyses and discussions are solely based on the estimation results of Model I reported in Table 3.

We first highlight the cross-sectional differences in default risk for different rating categories. The loading of each rating group on the common factor $\bar{H}_{i i}$ monotonically increases from 0.26 for AAA rating to 64.32 for CCC rating. These estimates are consistent with the idea that rating captures the relative ranking of default risk of borrowers and shows that rating is an important factor of capturing the cross-sectional variations of CDS spreads.

The highly significant parameter estimates of the transition matrix $\bar{Q}$ highlight the importance of rating changes. In Table 4, we translate these estimated parameters into the transition probabilities of rating changes over one year horizon. We find that ratings tend to be very stable and persistent. Under normal market conditions, a country has more than $90 \%$ probability to remain in its current rating over a one-year horizon. Rating transitions become more likely when the general level of default risk measured by the common factor increases. Ratings are also more stable under the physical than the risk-neutral measure.

Under our framework, credit risk has two components: default risk (measured by current credit rating) and rating transition risk due to rating upgrades or downgrades. To examine the importance of rating change, Table 5 reports the proportions of CDS spreads that are caused by potential rating transitions. It shows that the rating transition risk component tends to be a small percentage of the total CDS spread. On average, the portion of CDS spreads explained by rating transition risk is $10 \%$, which tends to be larger at short (1-year and 2-year ) and long (10-year) maturities. Moreover, the better the rating, the larger the fraction of CDS spread that can be explained by rating transition risk. The relatively small rating transition component of CDS spreads is consistent with the fact that the ratings for sovereigns are very stable with only 40 transitions for 34 countries over 8 years. Consistent with Pan and Singleton (2008) and Longstaff et al. (2011), our parameter estimates show that $\theta>\theta^{P}$ 
and $\kappa<\kappa^{P}$, suggesting that the default intensity has higher mean and is more persistent under the risk-neutral measure.

Table 6 reports the standard deviation of the pricing errors at different maturities for the 34 insample countries. The model fits most of the term structures quite well. We also find that $\sigma_{i M}$ increases as ratings become worse. In particular, for 1-year CDS contract on Greece, the average pricing error is close to 700 basis points. The pricing error, however, remains reasonable compared with the bid-ask spread of Greece during the ongoing European debt crisis: the 1-year CDS spreads of Greece exceed 10,000 basis points, and the bid-ask spreads exceed 1,000 basis points.

\subsection{In-Sample and Out-of-Sample Pricing Performance}

\subsubsection{Overall Performance}

While existing reduced-form models on sovereign credit risk are typically estimated using the CDS spreads of individual countries, the main purpose of our rating-based model is to price the CDS spreads of multiple countries simultaneously. Therefore, our model should be evaluated based on its overall performance for pricing the 34 in-sample and 34 out-of-sample countries.

The left (right) panel of Table 7 reports the mean absolute pricing error relative to the bid-ask spread for the 34 in-sample (out-of-sample) countries. We see in general the model pricing error is quite small compared with the bid-ask spreads. For most countries at intermediate maturities (2 to 7 years), the average absolute pricing errors are lower or at par with the average bid-ask spreads. The relative pricing errors are larger for 1-year and 10-year maturities, which tend to be less liquid than the other maturities. Notably, the pricing errors for the out-of-sample countries are generally smaller than that of the in-sample countries. One of the main reasons for this disparity is that the bid-ask spreads of CDS spreads for the out-of-sample countries are generally greater than that for the in-sample countries.

\subsubsection{Non-Eurozone Countries}

In this section, we report the pricing performance of our model for each of the 28 in-sample and 28 out-of-sample non-Eurozone countries. For each country, we provide time series plots of the average 
absolute pricing errors (across all maturities), the corresponding average bid-ask spreads, credit rating changes, positive/negative credit watches, and default events.

Figure 2 provides the results for 17 in-sample countries with relative small pricing errors. These countries include: Bulgaria, Chile, Croatia, Czech Republic, Iceland, Indonesia, Israel, Korea, Malaysia, Panama, Qatar, Romania, Russia, Slovakia, South Africa, Thailand, and Ukraine. Taking Chile as an example, while the rating at the end of the sample is $\mathrm{A}+$, the rating was A before it was upgraded on December 18, 2007. The general conclusion from these graphs is that our model can capture the CDS spreads of these countries quite well. The average absolute pricing errors are generally smaller than the average bid-ask spreads for most countries and most of the time, although the pricing errors become larger toward the end of the sample during the global financial crisis.

Figure 3 provides time series plots of the average absolute pricing errors of CDS spreads across all maturities for 28 out-of-sample countries, as well as the average bid-ask spreads for these countries. The countries represent all the non-Eurozone out-of-sample countries and include Abu Dhabi, Costa Rica, Cyprus, Dominican Republic, Ecuador, Egypt, El Salvador, Estonia, Guatemala, Hong Kong, Latvia, Lebanon, Morocco, New Zealand, Norway, Argentina, Australia, Bahrain, Denmark, Kazakhstan, Lithuania, Sweden, USA, Vietnam, Pakistan, Saudi Arabia, Slovenia, and Switzerland. Interestingly, our model seems to have better performances for these 28 out-of-sample countries than for the 17 in-sample countries. The pricing errors are generally smaller than the average bid-ask spreads for most of the 28 countries and most of the time.

The results in Figures 2 and 3 are notable because they show that a parsimonious model with only 16 parameters can capture the CDS spreads of the 17 in-sample and the 28 out-of-sample non-Eurozone countries reasonably well.

Figure 4 shows that our model does have relatively large pricing errors for the 11 in-sample countries, which include Brazil, China, Colombia, Hungary, Japan, Mexico, Peru, Philippines, Poland, Turkey, and Venezuela. These large pricing errors are indications that the underlying credit rating does not fully reflect the economic fundamentals of the borrowers or at least the economic fundamentals are inconsistent with that of other countries in similar rating categories. 
For example, some Latin American countries, such as Brazil, Colombia, Mexico, and Peru, tend to have large pricing errors in 2004 and 2005. The economic fundamentals of these countries have been consistently improved during this time given rising exports of natural resources and government policies that have resulted in lower deficits, more reserves, and rising local currencies. These countries actually end up buying back some of their Brady bonds issued in the 1990s. However, the credit ratings might not have fully reflected these positive signs on the fundamentals. For example, some market participants believe that Moody's and S\&P have underrated Brazil. Interestingly, the pricing errors of these countries decline toward the level of average bid-ask spreads after these countries have been gradually upgraded.

Meanwhile, for some countries, economic fundamentals might have been worse than that reflected in credit ratings. For example, while the Philippines has a BB rating in 2004, its economic fundamentals are much worse than those with similar or even worse credit ratings. For example, the country's debt-to-GDP ratio is more than $80 \%$ (could be $100 \%$ if the debt of some state firms are counted) with half denominated in foreign currencies. By contrast, countries with BB rating, such as Brazil, Turkey, Ukraine, and Vietnam, have a median debt-to-GDP ratio of $60 \%$. The debt-to-GDP ratio of the Philippines is even higher than that of some B-rated countries, such as Pakistan and Indonesia. We see a similar situation for Japan toward the end of the sample period. While Japan has a AA rating, the huge debt-to-GDP ratio and budget deficit dimmed the future prospect for the country's economic growth. As a result, the default risk of Japan is probably higher than that of the other AA-rated counties.

Some spikes in pricing errors are due to some dramatic events happened to the borrowing countries. For example, Venezuela had a spike in pricing error in 2005 because of a default event ("Selective Default" by S\&P). Hungary exhibits huge pricing errors around the time of its downgrading to junk status due to its vulnerable economic and financial conditions.

The relations between large model pricing errors and stale (inaccurate) ratings are best illustrated by the two rating upgrades for two in-sample countries: China and Poland. When China and Poland were upgraded from $\mathrm{BBB}+$ to $\mathrm{A}-$-, their absolute average pricing errors immediately declined toward the level of the average bid-ask spreads. Evidently BBB+ does not accurately reflect the credit risk 
of both countries. To understand the relation between the model pricing errors and rating staleness better, Figure 5 provides the pricing errors at different maturities for China and Poland before and after the rating changes. It shows that the decline in the pricing errors mainly comes from the model's improved performance in capturing the term structure of the CDS spreads after the rating changes.

\subsubsection{Eurozone Countries}

The Eurozone debt crisis poses serious challenges to any pricing model for sovereign CDS spreads. It is especially challenging for our rating-based model given a series of dramatic downgrades and negative credit watches of many countries during the crisis period. For example, on January 14, 2011, Fitch followed S\&P and Moody's in cutting the credit rating of Greece to junk. On June 13, 2011, S\&P downgraded Greece by three notches to CCC from B. On December 5, 2011, S\&P placed Germany, France, and 13 other Eurozone countries (Austria, Belgium, Finland, Luxemburg, Netherlands, Estonia, Ireland, Italy, Malta, Portugal, Slovak, Slovenia, and Spain) on negative credit watch. On January 13, 2012, S\&P cut the ratings of Italy, Spain, Portugal, and Cyprus by two notches and the standings of France, Austria, Malta, Slovakia, and Slovenia by one notch each. In this section, we examine the in-sample and out-of-sample pricing performance of our rating-based model for the 12 Eurozone countries.

We first consider the in-sample performance of our model for 6 Eurozone countries, which include Austria, Belgium, Germany, Greece, Italy, and Portugal. Figure 6 reports the time series of the average absolute pricing errors of CDS spreads and the average bid-ask spreads at different maturities. We find large pricing errors during the 2008 global financial crisis and the 2010-11 European debt crisis. The pricing errors are especially high for Greece and Portugal around the time that Greece was downgraded and other Eurozone countries were placed on negative credit watch.

Figure 7 reports the time series of average absolute pricing errors of CDS spreads at different maturities and the average bid-ask spreads at these maturities for 6 out-of-sample Eurozone countries, which include Finland, France, Ireland, Netherlands, Spain, and United Kingdom. The model has reasonable pricing performance for Finland and the Netherlands, which do not suffer from the struc- 
tural debt problem facing many other Eurozone countries. However, similar to the in-sample case, the pricing errors for the other four countries are much higher particularly around the Eurozone debt crisis. This is dramatically different from the out-of-sample performance of the non-Eurozone countries shown in Figure 3.

In general, our model can capture the CDS spreads for countries with stable ratings quite well. However, for countries that undergo dramatic rating changes, our model tends to have larger pricing errors. This feature of our model, however, does not necessarily represent a shortcoming. Large pricing error provides a warning sign to investors for potential rating changes in the near future. By contrast, although existing reduced-form models might be able to choose the latent factors to fit individual CDS spreads well, it would be difficult for these models to provide much insights on whether the changes in CDS spreads are actually due to changes in the economic fundamentals of the sovereign borrower.

\subsection{Nature of the Common Factor}

To understand the effect of the common factor on sovereign CDS spreads, we consider a special case of our in-sample model, denoted as the $z$-only model, by setting all the country-specific factors to zero. We regress the observed 5-year CDS spreads on the 5-year CDS spreads predicted by the z-only model. The left and right panels of Table 8 report the regression results for the in-sample and out-of-sample countries, respectively.

We find that the z-only model can explain on average about $60 \%$ of the variations of the CDS spreads of both the in-sample and out-of-sample countries. For example, the mean $R^{2}$ for the in-sample (out-of-sample) countries is $63 \%(61 \%)$, while the median $R^{2}$ for the in-sample (out-of-sample) countries is $71 \%(64 \%)$. These results are consistent with the conclusion of Pan and Singleton (2008) and Longstaff et al. (2011) that the majority of sovereign credit risk can be linked to a common factor. However, the way we model and estimate the common factor is different from that in existing sovereign credit risk models. ${ }^{14}$ Notably, this simple model with only one common factor and no country-specific

\footnotetext{
${ }^{14}$ For example, Ang and Longstaff (2013) take Germany and the US as the systemic factor the European countries and individual US states, respectively. We extend their analysis by allowing the possibility that each country has its own idiosyncratic default component. As shown in the table, the $R^{2} \mathrm{~s}$ for Germany and the US are $59 \%$ and $45 \%$, respectively, suggesting that
} 
factor on average can capture $60 \%$ of the variations of the CDS spreads of 68 countries. The excellent performance of the model is based on two important building blocks that capture the cross-sectional and time series variations of sovereign credit spreads.

We also find that the $z$-only model can capture the average level of the CDS spreads of both the in-sample and out-of-sample countries quite well. The estimated values of $\hat{\beta}$ in Table 8 are close to 1 , suggesting that rating is correctly priced on average. For example, the mean $\hat{\beta}$ for the in-sample (out-of-sample) countries is 1.08 (1.19), while the median $\hat{\beta}$ for the in-sample (out-of-sample) countries is 1.04 (1.19). However, for some specific countries, their respective ratings seem to mismatch their credit quality measured by their CDS spreads. Table 8 shows that most Eurozone countries, such as Austria, Belgium, Iceland, Portugal, France, UK, Spain, and Ireland, were significantly overrated, because their $\hat{\beta}$ s are significantly higher than 1 . This is consistent with the fact that most of these countries have inherent problems and were downgraded or placed on negative credit watch during the financial crisis. Meanwhile, countries with low $R^{2}$ s in Table 8, such as Colombia, Panama, and Indonesia, seem to be underrated.

Given the importance of the common factor, next we study the economic forces that drive the fluctuations of $z_{t}$, the market price of default risk $\lambda(t)$, and the credit risk premium. For maturity $\tau$ and credit rating $i$, the credit risk premium is defined as

$$
C R P_{i}(t, t+\tau) \equiv \frac{C D S_{i}(t, t+\tau)-C D S_{i}^{P}(t, t+\tau)}{C D S_{i}^{P}(t, t+\tau)}
$$

where $C D S_{i}(t, t+\tau)$ is the $\tau$-year CDS spreads, and $C D S_{i}^{P}(t, t+\tau)$ is the $\tau$-year CDS spreads obtained from (6) by setting the price of risk to be zero (e.g., setting $\lambda=\lambda_{z}=0$ in (8)).

Table 9 reports the regressions of $z_{t}, \lambda(t)$, and the credit risk premium on the VIX index, the 5-year constant maturity Treasury rates, and the CDX NA IG index individually and collectively. Individually, the VIX index and the Treasury rate can explain approximately $60 \%$ to $70 \%$ of the variations of the three variables, while the CDX NA IG index explains more than $70 \%$ of the variations of the three variables. Collectively, the three independent variables have highly significant $t$-statistics and can the CDS spreads of even the highest-rated countries contain significant idiosyncratic components. 
explain between $80 \%$ and $90 \%$ of the variations of the three risk measures. By including the returns on the S\&P 500 index, the DAX index, and the MSCI World index in Table 10, we cannot improve the $R^{2} \mathrm{~s}$ of the three risk measures anymore. One important advantage of our rating-based model is that we can use the CDS spreads of all in-sample countries jointly to estimate the common default factor, which significantly increases estimation efficiency. Thus, our model structure and estimation method significantly improve our ability to identify the common factor.

Figure 8 provides time series plots of $z_{t}, \lambda(t)$, and credit risk premium, as well as their corresponding predicted values based on the regressions in Table 9. Consistent with the high $R^{2} \mathrm{~s}$ in Table 9, we find that the actual and predicted values closely match each other. Panel A of Figure 8 shows that the common factor $z_{t}$ increases dramatically during the global financial crisis and the European debt crisis. Panel B of Figure 8 shows that during crisis time, the price of risk can be negative. Moreover, $\lambda(t)$ also exhibits a strong correlation with key financial variables, such as the VIX index and the US Treasury rates. Panel C of Figure 8 shows that the credit risk premium for 5-year CDS spread is negative when the credit environment is good (low $z_{t}$ ). The 5-year CRP becomes positive and higher when the credit environment is getting worse (high $z_{t}$ ). These observations show that the protection of sovereign credit risk is offered at discount (premium) when the default risk is low (high). Figure 9 reports the time series of the average credit risk premium $C R P$ at different maturities and ratings during our sample. Notably, the CRP increased dramatically during the global financial crisis and the European debt crisis. This is particularly more pronounced for CDS with better ratings and longer maturities.

\section{Conclusion}

In this paper, we developed a rating-based continuous-time model of sovereign credit risk that simultaneously captures the cross-sectional and time series properties of sovereign credit spreads and offers closed-form solutions for a wide range of credit derivatives. In our model, rating transition follows a continuous-time Markov chain, and countries with same credit rating share similar level of default risk. One of the greatest advantages of our approach is that it offers a parsimonious and unified frame- 
work to capture the credit risk of multiple countries. A simple version of our model, with only 16 parameters, one common and one country-specific factor, can simultaneously capture the term structure of CDS spreads of 34 in-sample and 34 out-of-sample countries well. On average, the common factor explains more than $60 \%$ of the variations of the CDS spreads of both the in-sample and out-ofsample countries, and more than $80 \%$ of the variations of the common factor is explained by the CBOE VIX index, the 5-year US Treasury rate, and the CDX NA IG Index. 


\section{References}

Afonso, A., D. Furceri, AND P. Gomes (2012): “Sovereign Credit Ratings and Financial Markets Linkages: Application to European Data," Journal of International Money and Finance, 31, 606-638.

Ang, A. And F. A. LOngStAfF (2013): "Systemic Sovereign Credit Risk: Lessons from the US and Europe," Journal of Monetary Economics, 60, 493-510.

Arvanitis, A., J. Gregory, And J. Laurent (1999): “Building Models for Credit Spreads,” Journal of Derivatives, 6, 27-43.

CANTOR, R. AND F. PACKER (1996): “Determinants and Impact of Sovereign Credit Ratings," Journal of Fixed Income, 6, 76-91.

Cox, J. C., J. E. Ingersoll, And S. A. Ross (1985): “A Theory of the Term Structure of Interest Rates," Econometrica, 53, 385-407.

DAS, S. AND P. HANOUnA (1996): “Pricing Credit-sensitive Debt when Interest Rates, Credit Ratings and Credit Spreads Are Stochastic," Journal of Financial Engineering, 5, 161-198.

Duffie, D., L. Pedersen, And K. Singleton (2003): “Modeling Sovereign Yield Spreads: A Case Study of Russian Debt," Journal of Finance, 58, 119-159.

DufFIE, D., L. SAITA, AND K. WANG (2007): "Multi-Period Corporate Failure Prediction with Stochastic Covariates," Journal of Financial Economics, 83, 635-665.

Duffie, D. And K. Singleton (1999): “Modeling Term Structures of Defaultable Bonds," Review of Financial Studies, 12, 687-720.

- (2003): Credit Risk: Pricing, Measurement, and Management, Princeton University Press.

FARNSWORTH, H. AND T. Li (2007): “The Dynamics of Credit Spreads and Ratings Migrations," Journal of Financial and Quantitative Analysis, 42, 595-620.

Huge, B. And D. LAndo (1999): “Swap Pricing with Two-sided Default Risk in a Rating-based Model," European Finance Review, 3, 239-268.

IsMAILESCU, I. AND H. KAZEMI (2010): “The Reaction of Emerging Market Credit Default Swap Spreads to Sovereign Credit Rating Changes," Journal of Banking and Finance, 34, 2861-2873.

JAMSHIDiAn, F. (1989): “An Exact Bond Option Formula,” Journal of Finance, 44, 205-209.

JARrow, R. A., D. LANDO, AND S. M. Turnbull (1997): “A Markov Model for the Term Structure of Credit Risk Spreads," Review of Financial Studies, 10, 481-523. 
KIfF, J., S. B. NowAK, AND L. Schumacher (2012): “Are Rating Agencies Powerful? An Investigation into the Impact and Accuracy of Sovereign Ratings," Tech. rep., International Monetary Fund.

KiJIMA, M. (1998): “Default Risk and Derivative Products," Mathematical Finance, 8, 229-247.

LANDO, D. (1998): “On Cox Process and Credit Risky Securities," Review of Derivatives Research, 2, 99-120.

LI, T. (2000): Essays in Financial Economics, Ph.D. dissertation, Washington University in St. Louis.

Longstaff, F., J. Pan, L. Pedersen, And K. Singleton (2011): “How Sovereign Is Sovereign Credit Risk?" American Economic Journal: Macroeconomics, 3, 75-103.

PAN, J. AND K. Singleton (2008): “Default and Recovery Implicit in the Term Structure of Sovereign CDS Spreads," Journal of Finance, 63, 2345-2384.

Remolona, E., M. Scatigna, And E. Wu (2008): “The Dynamic Pricing of Sovereign Risk in Emerging Markets," Journal of Fixed Income, 17, 57-71. 


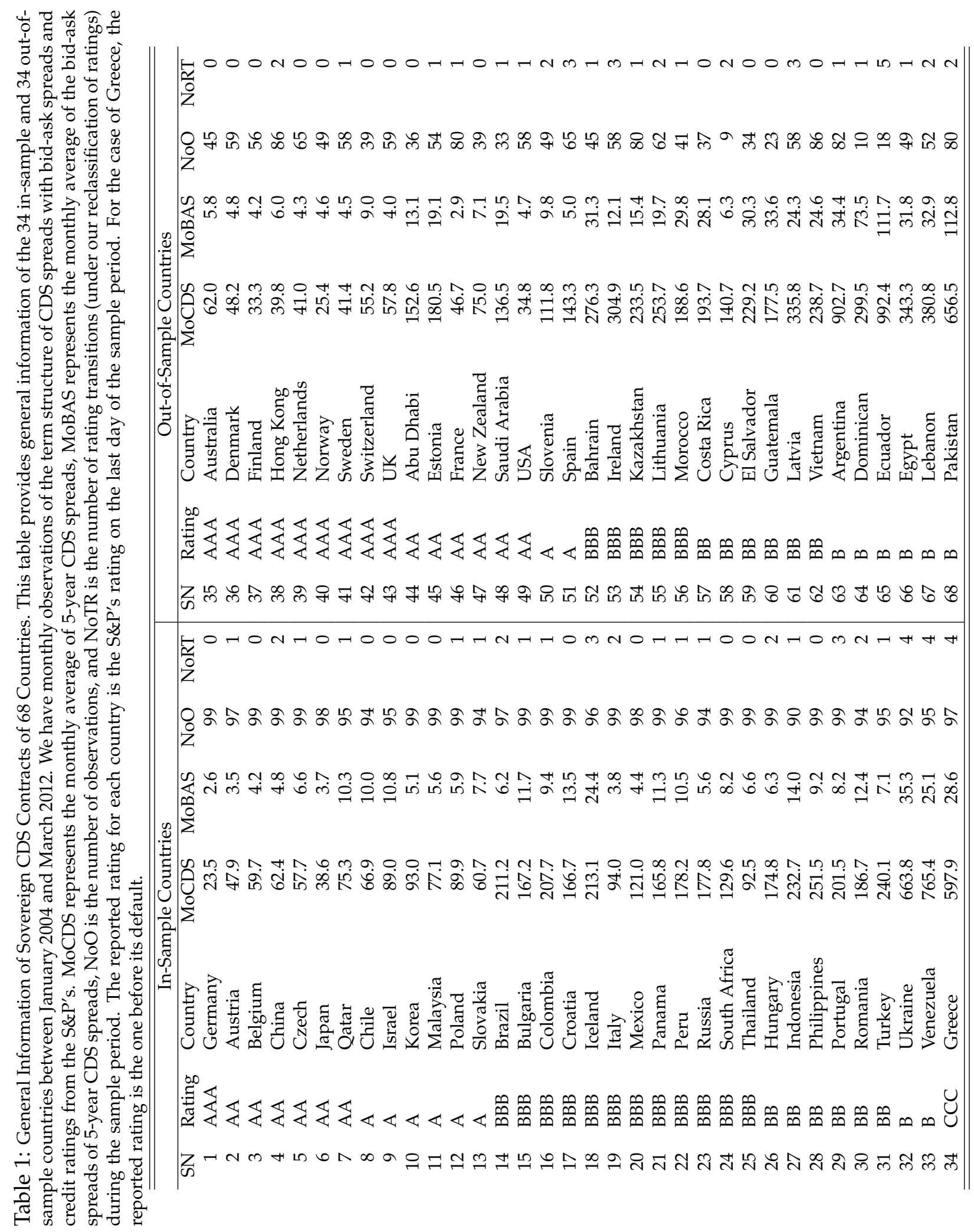




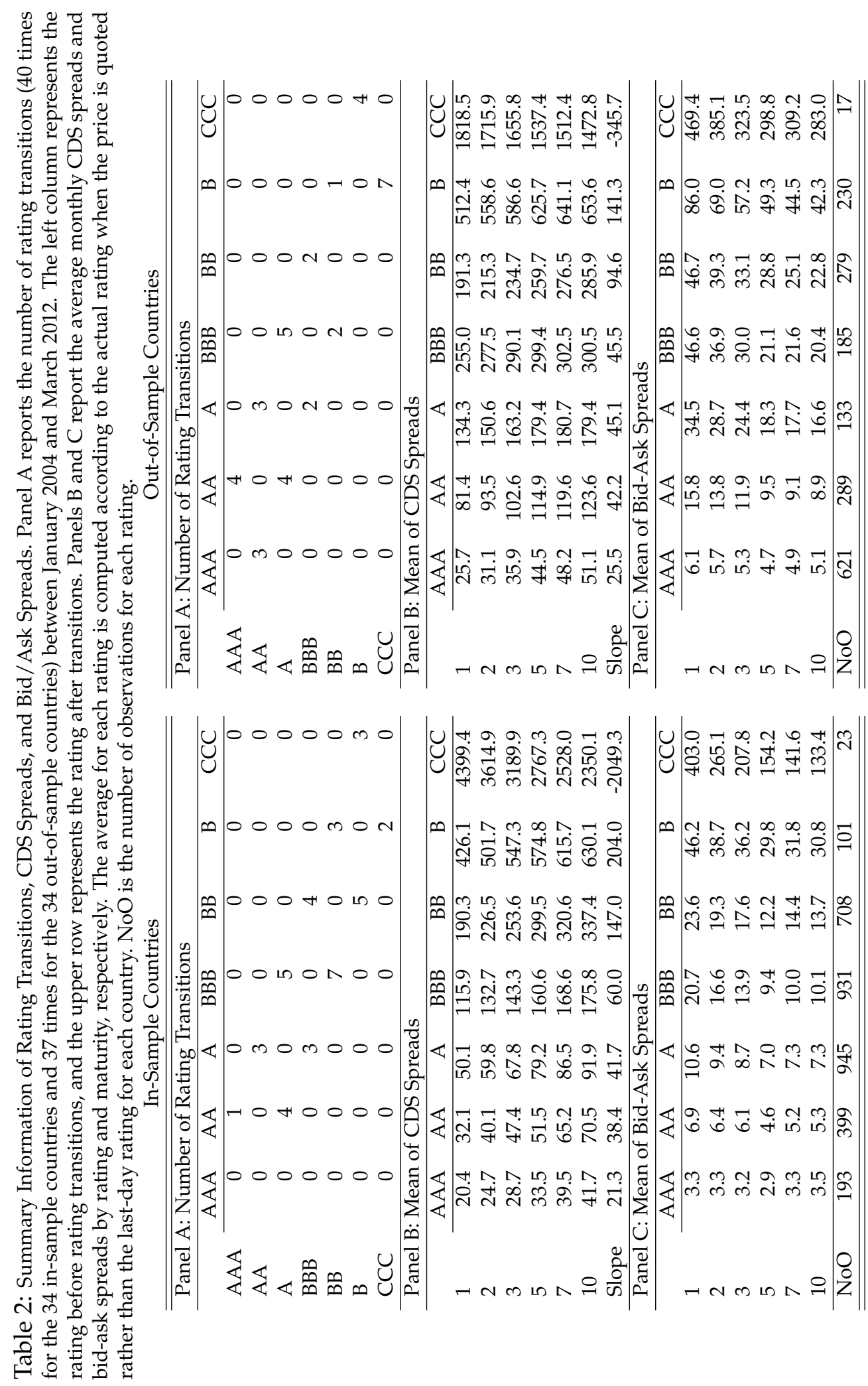


Table 3: Parameter Estimates of Rating-Based Sovereign CDS Models. Model I is the full model, Model II allows dependence of default risk on rating but no transitions between ratings, and Model III allows neither. Likelihood ratio test between Model I and Model II (III) has a $\chi^{2}$ distribution with 2 (8) degrees of freedom, with critical value at the 99.99 percentile of 18.42 (31.83). There is overwhelming evidence that both $\bar{Q}$ and $\bar{H}$ are important ingredients for CDS pricing.

\begin{tabular}{|c|c|c|c|c|c|}
\hline parameter & estimate & std. error & parameter & estimate & std. error \\
\hline \multicolumn{6}{|c|}{ Model I: full model } \\
\hline $\bar{Q}_{12}$ & 11.5093 & 0.4027 & $\kappa^{P}$ & 1.4183 & 0.0902 \\
\hline $\bar{Q}_{21}$ & 14.6147 & 0.5502 & $\theta^{P}$ & 0.0037 & 0.0005 \\
\hline $\bar{H}_{11}$ & 0.2632 & 0.0171 & $\sigma$ & 0.0360 & 0.0007 \\
\hline $\bar{H}_{22}$ & 0.3158 & 0.0147 & $\lambda$ & 0.0051 & 0.0015 \\
\hline $\bar{H}_{33}$ & 1.0000 & - & $\lambda_{z}$ & -1.4119 & 0.0390 \\
\hline $\bar{H}_{44}$ & 2.9327 & 0.0473 & $\kappa_{y}$ & 0.0482 & 0.0015 \\
\hline $\bar{H}_{55}$ & 5.1023 & 0.2708 & $\theta_{y}$ & 0.0356 & 0.0020 \\
\hline $\bar{H}_{66}$ & 8.9331 & 0.5382 & $\sigma_{y}$ & 0.0170 & 0.0004 \\
\hline $\bar{H}_{77}$ & 64.3189 & 3.8031 & LogLikeli & 1093.8 & - \\
\hline \multicolumn{6}{|c|}{ Model II: $\bar{Q}=0$} \\
\hline $\bar{H}_{11}$ & 0.4955 & 0.0129 & $\kappa^{P}$ & 2.8953 & 0.0093 \\
\hline $\bar{H}_{22}$ & 0.8332 & 0.0213 & $\theta^{P}$ & 0.0054 & 0.0002 \\
\hline $\bar{H}_{33}$ & 1.0000 & - & $\sigma$ & 0.0643 & 0.0006 \\
\hline $\bar{H}_{44}$ & 1.4972 & 0.0236 & $\lambda$ & 0.0156 & 0.0039 \\
\hline $\bar{H}_{55}$ & 4.6782 & 0.0317 & $\lambda_{z}$ & -2.8912 & 0.1003 \\
\hline $\bar{H}_{66}$ & 6.0383 & 0.1984 & $\kappa_{y}$ & 0.0520 & 0.0031 \\
\hline $\bar{H}_{77}$ & 7.2460 & 0.3992 & $\theta_{y}$ & 0.0630 & 0.0025 \\
\hline LogLikeli & 1078.4 & - & $\sigma_{y}$ & 0.0220 & 0.0010 \\
\hline \multicolumn{6}{|c|}{ Model III: $\bar{H}=I(\bar{Q}=0)$} \\
\hline$\kappa^{P}$ & 1.1795 & 0.0141 & $\kappa_{y}$ & 0.0404 & 0.0029 \\
\hline$\theta^{P}$ & 0.0113 & 0.0007 & $\theta_{y}$ & 0.0886 & 0.0028 \\
\hline$\sigma$ & 0.0532 & 0.0020 & $\sigma_{y}$ & 0.0270 & 0.0009 \\
\hline$\lambda$ & 0.0133 & 0.0030 & LogLikeli & 946.34 & - \\
\hline$\lambda_{z}$ & -1.1749 & 0.0365 & & & \\
\hline \multicolumn{6}{|c|}{ Likelihood Ratio Test: } \\
\hline \multirow{2}{*}{\multicolumn{2}{|c|}{$\begin{array}{r}99 \text { percentile of } \chi^{2}(2) \\
99.99 \text { percentile of } \chi^{2}(2)\end{array}$}} & 9.22 & \multirow{2}{*}{\multicolumn{3}{|c|}{$\begin{array}{l}\text { Model I vs Model II: tested value } \\
2 \times(1093.8-1078.4)=30.80\end{array}$}} \\
\hline & & 18.42 & & & \\
\hline \multicolumn{2}{|c|}{99 percentile of $\chi^{2}(8)$} & 20.09 & \multicolumn{3}{|c|}{ Model I vs Model III: tested value } \\
\hline \multicolumn{2}{|c|}{99.99 percentile of $\chi^{2}(8)$} & 31.83 & \multicolumn{3}{|c|}{$2 \times(1093.8-946.34)=294.9$} \\
\hline
\end{tabular}


Table 4: One-Year Rating Transition Probabilities. Rating transition probabilities are computed under the risk-neutral and physical measures at the estimated model parameters and different levels of the common factor. That is, $\exp (\bar{Q} z)$ for $z=\theta^{P}, \theta, \min \left(z_{t}\right)$, and $\max \left(z_{t}\right)$.

\begin{tabular}{l|rrrrrrr|rrrrrrr}
\hline \hline & \multicolumn{7}{|c|}{ Under Physical Measure $\theta^{P}=0.0037$} & \multicolumn{5}{c}{ Under Risk-Neutral Measure $\theta=0.0286$} \\
\hline Ratings & AAA & AA & A & BBB & BB & B & CCC & AAA & AA & A & BBB & BB & B & CCC \\
\hline AAA & 96.5 & 3.5 & 0.1 & 0 & 0 & 0 & 0 & 76.4 & 20.2 & 3.1 & 0.3 & 0 & 0 & 0 \\
AA & 4.4 & 92.1 & 3.4 & 0.1 & 0 & 0 & 0 & 25.7 & 54.6 & 16.7 & 2.7 & 0.3 & 0 & 0 \\
A & 0.1 & 4.3 & 92.1 & 3.4 & 0.1 & 0 & 0 & 4.9 & 21.2 & 54.1 & 16.7 & 2.7 & 0.3 & 0 \\
BBB & 0 & 0.1 & 4.3 & 92.1 & 3.4 & 0.1 & 0 & 0.7 & 4.3 & 21.2 & 54.1 & 16.7 & 2.7 & 0.3 \\
BB & 0 & 0 & 0.1 & 4.3 & 92.1 & 3.4 & 0.1 & 0.1 & 0.6 & 4.3 & 21.2 & 54.1 & 16.7 & 3.0 \\
B & 0 & 0 & 0 & 0.1 & 4.3 & 92.1 & 3.5 & 0 & 0.1 & 0.6 & 4.3 & 21.2 & 54.5 & 19.3 \\
CCC & 0 & 0 & 0 & 0 & 0.1 & 4.4 & 95.5 & 0 & 0 & 0.1 & 0.6 & 4.8 & 24.5 & 70.0 \\
\hline Ratings & \multicolumn{1}{|c}{ Tranquil Period $\min \left(z_{t}\right)=0.0018$} & & \multicolumn{4}{c}{ Turbulent Period max $\left(z_{t}\right)=0.0285$} & \\
\hline AAA & 97.9 & 2.1 & 0 & 0 & 0 & 0 & 0 & 76.4 & 20.2 & 3.1 & 0.3 & 0 & 0 & 0 \\
AA & 2.6 & 95.4 & 2.0 & 0 & 0 & 0 & 0 & 25.6 & 54.7 & 16.7 & 2.7 & 0.3 & 0 & 0 \\
A & 0 & 2.6 & 95.3 & 2.0 & 0 & 0 & 0 & 4.9 & 21.2 & 54.2 & 16.7 & 2.7 & 0.3 & 0 \\
BBB & 0 & 0 & 2.6 & 95.3 & 2.0 & 0 & 0 & 0.7 & 4.3 & 21.2 & 54.2 & 16.7 & 2.7 & 0.3 \\
BB & 0 & 0 & 0 & 2.6 & 95.3 & 2.0 & 0 & 0.1 & 0.6 & 4.3 & 21.2 & 54.2 & 16.7 & 3.0 \\
B & 0 & 0 & 0 & 0 & 2.6 & 95.4 & 2.0 & 0 & 0.1 & 0.6 & 4.3 & 21.2 & 54.5 & 19.3 \\
CCC & 0 & 0 & 0 & 0 & 0 & 2.6 & 97.4 & 0 & 0 & 0.1 & 0.6 & 4.8 & 24.5 & 70.1 \\
\hline \hline
\end{tabular}


Table 5: Proportion of Model Implied CDS Spread Due to Rating Transition Risk. For each country and at each maturity, we report the time series average of the ratio $\left|C D S^{0}-C D S\right| / C D S$, where $C D S$ is the model implied CDS spread and $C D S^{0}$ is obtained by setting $\bar{Q} \equiv 0$ in the CDS pricing formula, given the in-sample estimated values of $z$ and $y_{i}$. The first column reports the last-day rating for each country. The average for each rating is computed according to the actual rating when the price is quoted rather than the last-day rating for each country.

\begin{tabular}{|c|c|c|c|c|c|c|c|c|}
\hline Rating & Country & $1 y$ & $2 y$ & $3 y$ & $5 y$ & $7 y$ & $10 y$ & Mean \\
\hline AAA & Germany & 0.443 & 0.336 & 0.395 & 0.025 & 0.104 & 0.230 & 0.256 \\
\hline AA & Austria & 0.298 & 0.249 & 0.447 & 0.043 & 0.097 & 0.216 & 0.225 \\
\hline AA & Belgium & 0.481 & 0.287 & 0.178 & 0.035 & 0.167 & 0.273 & 0.237 \\
\hline AA & China & 0.433 & 0.238 & 0.091 & 0.025 & 0.085 & 0.131 & 0.167 \\
\hline AA & Czech & 0.340 & 0.240 & 0.363 & 0.025 & 0.106 & 0.161 & 0.206 \\
\hline AA & Japan & 0.591 & 0.515 & 0.397 & 0.032 & 0.170 & 0.286 & 0.332 \\
\hline AA & Qatar & 0.382 & 0.219 & 0.103 & 0.034 & 0.118 & 0.195 & 0.175 \\
\hline A & Chile & 0.452 & 0.205 & 0.088 & 0.026 & 0.086 & 0.133 & 0.165 \\
\hline A & Israel & 0.277 & 0.141 & 0.066 & 0.025 & 0.079 & 0.122 & 0.118 \\
\hline A & Korea & 0.301 & 0.154 & 0.070 & 0.025 & 0.079 & 0.123 & 0.125 \\
\hline A & Malaysia & 0.323 & 0.167 & 0.075 & 0.025 & 0.082 & 0.127 & 0.133 \\
\hline A & Poland & 0.220 & 0.170 & 0.087 & 0.022 & 0.057 & 0.081 & 0.106 \\
\hline A & Slovakia & 0.319 & 0.220 & 0.334 & 0.022 & 0.087 & 0.129 & 0.185 \\
\hline BBB & Brazil & 0.111 & 0.049 & 0.022 & 0.017 & 0.026 & 0.036 & 0.044 \\
\hline BBB & Bulgaria & 0.042 & 0.055 & 0.018 & 0.009 & 0.012 & 0.015 & 0.025 \\
\hline BBB & Colombia & 0.161 & 0.059 & 0.029 & 0.025 & 0.035 & 0.045 & 0.059 \\
\hline BBB & Croatia & 0.034 & 0.034 & 0.015 & 0.008 & 0.010 & 0.013 & 0.019 \\
\hline BBB & Iceland & 0.127 & 0.099 & 0.066 & 0.009 & 0.042 & 0.074 & 0.069 \\
\hline BBB & Italy & 0.442 & 0.327 & 0.191 & 0.021 & 0.106 & 0.173 & 0.210 \\
\hline BBB & Mexico & 0.023 & 0.014 & 0.011 & 0.009 & 0.010 & 0.017 & 0.014 \\
\hline BBB & Panama & 0.163 & 0.070 & 0.029 & 0.024 & 0.035 & 0.044 & 0.061 \\
\hline BBB & Peru & 0.136 & 0.055 & 0.024 & 0.018 & 0.028 & 0.036 & 0.050 \\
\hline BBB & Russia & 0.023 & 0.016 & 0.011 & 0.010 & 0.012 & 0.017 & 0.015 \\
\hline BBB & South Africa & 0.017 & 0.016 & 0.011 & 0.009 & 0.009 & 0.016 & 0.013 \\
\hline BBB & Thailand & 0.062 & 0.029 & 0.015 & 0.009 & 0.011 & 0.018 & 0.024 \\
\hline BB & Hungary & 0.189 & 0.161 & 0.055 & 0.011 & 0.032 & 0.052 & 0.083 \\
\hline BB & Indonesia & 0.265 & 0.093 & 0.035 & 0.039 & 0.048 & 0.057 & 0.089 \\
\hline BB & Philippines & 0.115 & 0.052 & 0.029 & 0.028 & 0.036 & 0.047 & 0.051 \\
\hline BB & Portugal & 0.401 & 0.339 & 0.148 & 0.019 & 0.102 & 0.172 & 0.197 \\
\hline BB & Romania & 0.121 & 0.126 & 0.033 & 0.020 & 0.026 & 0.030 & 0.059 \\
\hline BB & Turkey & 0.103 & 0.050 & 0.028 & 0.027 & 0.035 & 0.045 & 0.048 \\
\hline B & Ukraine & 0.152 & 0.065 & 0.036 & 0.031 & 0.049 & 0.074 & 0.068 \\
\hline B & Venezuela & 0.146 & 0.079 & 0.024 & 0.030 & 0.044 & 0.051 & 0.062 \\
\hline CCC & Greece & 0.173 & 0.285 & 0.250 & 0.023 & 0.084 & 0.126 & 0.157 \\
\hline- & AAA & 0.370 & 0.295 & 0.429 & 0.034 & 0.099 & 0.222 & 0.241 \\
\hline - & AA & 0.543 & 0.407 & 0.247 & 0.030 & 0.158 & 0.265 & 0.275 \\
\hline - & A & 0.330 & 0.206 & 0.159 & 0.024 & 0.087 & 0.133 & 0.156 \\
\hline - & BBB & 0.025 & 0.027 & 0.017 & 0.010 & 0.010 & 0.016 & 0.018 \\
\hline - & BB & 0.143 & 0.070 & 0.030 & 0.026 & 0.037 & 0.044 & 0.058 \\
\hline - & B & 0.368 & 0.123 & 0.045 & 0.044 & 0.063 & 0.083 & 0.121 \\
\hline- & CCC & 0.174 & 0.144 & 0.030 & 0.059 & 0.113 & 0.168 & 0.115 \\
\hline - & Overall & 0.221 & 0.142 & 0.108 & 0.022 & 0.061 & 0.097 & 0.109 \\
\hline
\end{tabular}


Table 6: Estimated Standard Deviations of Pricing Errors $\sigma_{j M}$ Across Countries and Maturities. The first column reports the last-day rating for each country. The average for each rating is computed according to the last-day rating for each country. The sample consists of monthly observations between January 2004 and March 2012.

\begin{tabular}{|c|c|c|c|c|c|c|c|}
\hline Rating & Country & $1 \mathrm{y}$ & $2 y$ & $3 y$ & $5 y$ & $7 y$ & $10 y$ \\
\hline AAA & Germany & 9.2 & 7.3 & 4.6 & 5.2 & 7.3 & 9.7 \\
\hline AA & Austria & 10.6 & 8.1 & 5.8 & 7.4 & 7.9 & 12.6 \\
\hline AA & Belgium & 15.2 & 9.9 & 9.6 & 6.4 & 10.0 & 17.1 \\
\hline AA & China & 14.3 & 9.3 & 5.6 & 6.3 & 10.1 & 13.1 \\
\hline AA & Czech & 13.1 & 6.8 & 3.4 & 5.5 & 7.3 & 10.9 \\
\hline AA & Japan & 13.9 & 9.0 & 5.0 & 6.3 & 9.9 & 12.2 \\
\hline AA & Qatar & 13.0 & 7.2 & 3.9 & 5.8 & 7.3 & 11.4 \\
\hline A & Chile & 12.2 & 7.3 & 3.0 & 6.2 & 7.7 & 8.9 \\
\hline A & Israel & 17.7 & 8.6 & 3.4 & 8.3 & 9.3 & 11.7 \\
\hline A & Korea & 14.1 & 10.0 & 5.7 & 6.7 & 10.6 & 12.6 \\
\hline A & Malaysia & 13.1 & 9.6 & 4.5 & 6.9 & 8.5 & 13.1 \\
\hline A & Poland & 28.2 & 12.9 & 5.7 & 9.2 & 15.8 & 21.1 \\
\hline A & SI & 16.5 & 9.9 & 4.8 & 5.6 & 10.4 & 15.9 \\
\hline BBB & Brazil & 70.4 & 34.6 & 15.4 & 25.0 & 38.7 & 51.3 \\
\hline BBB & Bulgaria & 31.3 & 13.6 & 7.4 & 10.9 & 15.9 & 24.5 \\
\hline BBB & Colombia & 63.4 & 38.4 & 15.9 & 24.7 & 38.2 & 50.3 \\
\hline BBB & c & 35.7 & 15.4 & 8.8 & 11.1 & 18.3 & 28.3 \\
\hline BBB & Is & 76.1 & 40.7 & 7.3 & 20.4 & 40.5 & 54.5 \\
\hline BBB & Italy & 20.7 & 8.4 & 5.6 & 9.0 & 10.1 & 11.3 \\
\hline BBB & Texico & 20.3 & 11.8 & 8.0 & 6.4 & 11.9 & 21.8 \\
\hline BBB & Panan & 39.0 & 23.9 & 13.8 & 12.7 & 24.2 & 39.1 \\
\hline BBB & $\mathrm{P}$ & 49.8 & 31.9 & 13.4 & 19.3 & 31.6 & 42.1 \\
\hline BBB & ( cis & 51.4 & 21.2 & 8.5 & 23.3 & 27.9 & 25.4 \\
\hline BBB & S & 23.5 & 14.0 & 7.5 & 9.0 & 13.2 & 23.1 \\
\hline BBB & Thailand & 18.3 & 11.0 & 5.6 & 6.4 & 11.8 & 16.9 \\
\hline BB & & 37.3 & 16.5 & 7.1 & 14.3 & 19.4 & 25.4 \\
\hline BB & donesia & 36.8 & 27.3 & 16.8 & 11.4 & 25.7 & 42.8 \\
\hline BB & & 68.8 & 42.9 & 20.4 & 27.0 & 41.5 & 60.9 \\
\hline BB & & 78.8 & 90.1 & 43.7 & 35.8 & 71.0 & 90.2 \\
\hline BB & mania & 36.7 & 21.1 & 11.8 & 15.0 & 23.0 & 32.0 \\
\hline BB & & 44.6 & 27.1 & 14.6 & 15.2 & 26.9 & 41.3 \\
\hline B & Ukra & 142.2 & 76.2 & 37.8 & 49.7 & 75.2 & 112.0 \\
\hline B & Venezuela & 102.9 & 53.3 & 32.5 & 35.4 & 53.1 & 80.1 \\
\hline CCC & Greece & 686.3 & 170.8 & 65.7 & 213.2 & 282.7 & 309.6 \\
\hline Average & AAA & 9.2 & 7.3 & 4.6 & 5.2 & 7.3 & 9.7 \\
\hline Averag & AA & 13.4 & 8.4 & 5.5 & 6.3 & 8.7 & 12.9 \\
\hline Average & A & 17.0 & 9.7 & 4.5 & 7.2 & 10.4 & 13.9 \\
\hline Average & BBB & 41.7 & 22.1 & 9.8 & 14.8 & 23.5 & 32.4 \\
\hline Average & BB & 50.5 & 37.5 & 19.1 & 19.8 & 34.6 & 48.8 \\
\hline Average & B & 122.5 & 64.7 & 35.1 & 42.6 & 64.2 & 96.0 \\
\hline & & 56.6 & 26.7 & 12.7 & 20.0 & 30.1 & 39.8 \\
\hline Overall & SD & 115.2 & 32.2 & 13.4 & 35.7 & 48.0 & 53.7 \\
\hline Overall & Min & 9.2 & 6.8 & 3.0 & 5.2 & 7.3 & 8.9 \\
\hline Overall & Med & 29.7 & 13.8 & 7.4 & 10.0 & 15.8 & 23.8 \\
\hline Overall & $\operatorname{Max}$ & 686.3 & 170.8 & 65.7 & 213.2 & 282.7 & 309.6 \\
\hline
\end{tabular}


Table 7: Mean Absolute Pricing Error Relative to Bid-Ask Spread for In-Sample and Out-of-Sample Countries. We also report the last-day rating for each country. The average for each rating is computed according to the actual rating when the price is quoted rather than the last-day rating for each country. The sample consists of monthly observations between January 2004 and March 2012.

\begin{tabular}{|c|c|c|c|c|c|c|c|c|c|c|c|c|c|c|c|}
\hline \multicolumn{8}{|c|}{ In-Sample Countries } & \multicolumn{8}{|c|}{ Out-of-Sample Countries } \\
\hline Rating & Country & $1 \mathrm{y}$ & $2 y$ & $3 \mathrm{y}$ & $5 y$ & $7 y$ & $10 \mathrm{y}$ & Rating & Country & $1 \mathrm{y}$ & $2 \mathrm{y}$ & $3 y$ & $5 y$ & $7 y$ & $10 \mathrm{y}$ \\
\hline AAA & Germany & 3.2 & 2.3 & 1.2 & 1.2 & 1.8 & 2.4 & AAA & Australia & 0.9 & 0.5 & 0.4 & 1.0 & 0.7 & 1.0 \\
\hline AA & Austria & 1.7 & 1.3 & 0.7 & 1.1 & 1.3 & 1.8 & AAA & Denmark & 1.8 & 0.8 & 0.5 & 0.9 & 1.0 & 1.4 \\
\hline AA & Belgium & 1.4 & 0.9 & 1.0 & 0.8 & 1.2 & 2.2 & AAA & Finland & 2.7 & 1.0 & 0.5 & 1.0 & 1.0 & 1.3 \\
\hline AA & China & 2.1 & 1.7 & 0.9 & 1.3 & 1.7 & 2.2 & AAA & Hong Kong & 0.7 & 0.6 & 0.4 & 0.4 & 0.9 & 1.2 \\
\hline AA & Czech & 1.0 & 0.7 & 0.5 & 0.7 & 1.3 & 2.2 & AAA & Netherlands & 1.7 & 1.0 & 0.5 & 0.9 & 1.1 & 1.4 \\
\hline AA & Japan & 4.5 & 2.2 & 1.1 & 1.2 & 2.0 & 2.4 & AAA & Norway & 1.2 & 1.0 & 0.6 & 0.7 & 0.8 & 1.2 \\
\hline AA & Qatar & 0.9 & 0.6 & 0.3 & 0.6 & 0.7 & 1.0 & AAA & Sweden & 2.1 & 1.3 & 0.5 & 1.1 & 1.1 & 1.4 \\
\hline A & Chile & 1.0 & 0.6 & 0.2 & 0.5 & 0.6 & 0.7 & AAA & Switzerland & 1.0 & 0.8 & 0.4 & 0.7 & 0.9 & 0.8 \\
\hline A & Israel & 1.4 & 0.7 & 0.3 & 0.7 & 0.8 & 1.0 & AAA & UK & 4.5 & 2.8 & 1.2 & 2.0 & 1.9 & 1.8 \\
\hline A & Korea & 1.5 & 1.1 & 0.7 & 0.8 & 1.4 & 1.8 & AA & Abu Dhabi & 1.8 & 1.3 & 0.6 & 0.8 & 1.1 & 2.0 \\
\hline A & Malay & 2.1 & 1.4 & 0.6 & 1.0 & 1.2 & 1.7 & AA & Estc & 1.7 & 0.8 & 0.5 & 0.9 & 1.2 & 1.6 \\
\hline A & Poland & 2.7 & 1.3 & 0.8 & 2.0 & 2.9 & 3.9 & AA & Frar & 2.7 & 1.8 & 0.8 & 1.6 & 1.6 & 1.8 \\
\hline A & Slovakia & 0.8 & 0.8 & 0.6 & 0.8 & 1.5 & 2.4 & AA & New Zealand & 0.5 & 0.7 & 0.9 & 0.4 & 0.9 & 2.3 \\
\hline BBB & Brazil & 4.2 & 2.9 & 1.5 & 2.6 & 3.0 & 5.0 & AA & Saudi Arabia & 0.5 & 0.5 & 0.2 & 0.4 & 0.6 & 1.1 \\
\hline BBB & Bulg & 1.8 & 1.1 & 0.5 & 1.2 & 1.8 & 2.5 & AA & & 0.7 & 0.7 & 0.6 & 0.5 & 0.9 & 1.5 \\
\hline BBB & Colc & 3.6 & 2.2 & 1.1 & 1.6 & 2.5 & 3.5 & $\mathrm{~A}$ & enia & 1.5 & 0.8 & 0.3 & 0.9 & 1.0 & 1.2 \\
\hline BBB & Croa & 1.4 & 0.9 & 0.5 & 0.9 & 1.5 & 2.1 & A & Spa & 1.9 & 1.5 & 1.3 & 1.6 & 1.8 & 2.8 \\
\hline BBB & Icela & 0.7 & 0.7 & 0.3 & 0.5 & 1.2 & 1.8 & BBB & & 0.8 & 0.4 & 0.3 & 0.7 & 0.6 & 1.1 \\
\hline BBB & Italy & 1.7 & 1.0 & 0.8 & 1.4 & 1.4 & 1.8 & BBB & & 1.0 & 1.2 & 1.1 & 1.2 & 2.2 & 3.1 \\
\hline BBB & Mex & 2.5 & 1.5 & 1.0 & 1.4 & 1.7 & 2.9 & BBB & khstan & 2.4 & 0.9 & 0.4 & 1.3 & 1.4 & 2.0 \\
\hline BBB & Panama & 1.8 & 1.0 & 0.6 & 0.7 & 1.3 & 2.1 & BBB & Lithuania & 1.5 & 1.0 & 0.5 & 0.8 & 1.6 & 2.5 \\
\hline BBB & Peru & 2.3 & 1.3 & 0.7 & 1.0 & 1.5 & 2.5 & BBB & & 0.8 & 0.6 & 0.3 & 0.3 & 1.0 & 1.5 \\
\hline BBB & Russ & 3.7 & 1.4 & 0.7 & 2.4 & 2.6 & 3.3 & BB & a Rica & 1.0 & 1.0 & 0.7 & 0.3 & 1.0 & 1.7 \\
\hline BBB & South Africa & 2.4 & 1.4 & 0.6 & 1.3 & 1.5 & 2.3 & BB & & 0.8 & 1.0 & 0.7 & 1.1 & 2.0 & 2.9 \\
\hline BBB & Thailand & 1.7 & 1.4 & 0.6 & 1.0 & 1.5 & 2.1 & BB & lvador & 1.1 & 0.5 & 0.3 & 0.6 & 0.7 & 1.2 \\
\hline BB & & 2.2 & 1.2 & 0.6 & 1.7 & 2.1 & 2. & BB & c & 0.7 & 0.6 & 0.3 & 0.3 & 0.7 & 0.9 \\
\hline BB & Indo & 1.5 & 1.2 & 1.3 & 0.9 & 1.3 & 2. & BB & & 1.5 & 1.2 & 0.6 & 1.2 & 1.9 & 2.4 \\
\hline BB & Philippines & 2.8 & 2.2 & 1.6 & 2.0 & 2.2 & 3.7 & BB & & 1.1 & 0.8 & 0.4 & 0.8 & 1.3 & 1.7 \\
\hline BB & Portugal & 1.1 & 0.9 & 0.8 & 1.0 & 1.7 & 2.2 & & Argentina & 2.9 & 1.7 & 1.1 & 1.7 & 2.3 & 3.9 \\
\hline BB & & 1.8 & 1.4 & 0.6 & 1.3 & 2.4 & 3. & & ican & 0.2 & 0.1 & 0.1 & 0.1 & 0.1 & 0.3 \\
\hline BB & Turl & 4.1 & 3.4 & 1.9 & 2.5 & 3.6 & 6.2 & & dor & 4.0 & 2.5 & 1.1 & 2.6 & 4.9 & 7.3 \\
\hline B & Ukra & 1.9 & 1.7 & 1.1 & 1.3 & 2.1 & 3.6 & & Egy & 1.0 & 0.7 & 0.5 & 0.6 & 1.1 & 1.6 \\
\hline B & Venezuela & 2.4 & 1.7 & 1.0 & 1.6 & 2.5 & 4.0 & & & 1.6 & 1.0 & 0.9 & 1.0 & 1.6 & 2.1 \\
\hline CCC & & 1.4 & 1.2 & 0.6 & 2.0 & 3.0 & 3.4 & B & & 1.3 & 0.8 & 0.5 & 0.5 & 1.1 & 1.2 \\
\hline- & $\mathrm{AA}$ & 2.4 & 1.7 & 0.9 & 1.1 & 1.5 & 2.1 & - & AA & 1.2 & 0.9 & 0.5 & 0.7 & 1.1 & 1.6 \\
\hline- & AA & 2.3 & 1.3 & 0.8 & 0.9 & 1.3 & 1.9 & - & AA & 1.6 & 1.2 & 0.8 & 1.1 & 1.7 & 2.6 \\
\hline- & A & 1.4 & 0.9 & 0.5 & 0.9 & 1.3 & 1.7 & - & A & 1.5 & 1.0 & 0.6 & 0.9 & 1.4 & 2.1 \\
\hline- & $\mathrm{BBl}$ & 2.2 & 1.3 & 0.7 & 1.4 & 2.0 & 2.9 & - & BBB & 1.5 & 0.8 & 0.5 & 0.9 & 1.0 & 1.4 \\
\hline- & BB & 2.7 & 2.1 & 1.3 & 1.7 & 2.4 & 4.0 & - & BB & 2.1 & 1.3 & 0.6 & 1.1 & 1.3 & 1.7 \\
\hline - & B & 2.5 & 1.2 & 0.7 & 1.4 & 2.0 & 2.8 & - & B & 0.8 & 0.7 & 0.7 & 0.4 & 0.9 & 1.5 \\
\hline - & CCC & 1.7 & 1.0 & 0.4 & 2.0 & 2.9 & 3.4 & - & CCC & 0.4 & 0.4 & 0.5 & 0.4 & 0.3 & 1.1 \\
\hline- & Overall & 2.1 & 1.4 & 0.8 & 1.3 & 1.8 & 2.6 & - & Overall & 1.6 & 1.0 & 0.6 & 1.0 & 1.3 & 1.8 \\
\hline
\end{tabular}


Table 8: OLS Regression of Observed 5-Year CDS Spreads on CDS Spreads Implied by the $z$-Only Model. We obtain the $z$ only model by setting the country-specific factors to zero in Model I estimated using the 34 in-sample countries. The average for each rating is computed according to the last-day rating for each country. The sample consists of monthly observations between January 2004 and March 2012.

\begin{tabular}{|c|c|c|c|c|c|c|c|c|c|}
\hline \multicolumn{5}{|c|}{ In-Sample Countries } & \multicolumn{5}{|c|}{ Out-of-Sample Countries } \\
\hline Rating & Country & $\hat{\beta}$ & $t$-stat. & $R^{2}$ & Rating & Country & $\hat{\beta}$ & $t$-stat. & $R^{2}$ \\
\hline AAA & Germany & 1.27 & 11.9 & 0.59 & AAA & Australia & 1.36 & 10.0 & 0.70 \\
\hline AA & Austria & 2.88 & 16.9 & 0.75 & AAA & Denmark & 1.86 & 11.4 & 0.70 \\
\hline AA & Belgium & 2.08 & 9.0 & 0.46 & AAA & Finland & 0.95 & 9.4 & 0.62 \\
\hline AA & China & 0.73 & 10.5 & 0.53 & AAA & Hong Kong & 1.26 & 13.7 & 0.69 \\
\hline AA & Czech & 1.08 & 16.6 & 0.74 & AAA & Netherlands & 1.55 & 11.5 & 0.68 \\
\hline AA & Japan & 1.04 & 9.4 & 0.48 & AAA & Norway & 0.53 & 8.1 & 0.58 \\
\hline AA & Qatar & 2.11 & 12.5 & 0.63 & AAA & Sweden & 1.50 & 11.8 & 0.71 \\
\hline A & Chile & 0.98 & 26.7 & 0.89 & AAA & Switzerland & 1.49 & 7.1 & 0.58 \\
\hline A & Israel & 1.02 & 19.6 & 0.81 & AAA & UK & 1.49 & 8.8 & 0.58 \\
\hline A & Korea & 1.52 & 20.2 & 0.81 & AA & Abu Dhabi & 1.54 & 4.5 & 0.38 \\
\hline A & Malaysia & 1.08 & 22.6 & 0.84 & AA & Estonia & 2.61 & 13.7 & 0.78 \\
\hline A & Poland & 1.37 & 11.3 & 0.57 & AA & France & 2.02 & 8.5 & 0.48 \\
\hline A & Slovakia & 1.01 & 11.8 & 0.60 & AA & New Zealand & 1.12 & 9.4 & 0.70 \\
\hline $\mathrm{BBB}$ & Brazil & 0.79 & 7.3 & 0.36 & AA & Saudi Arabia & 1.45 & 7.8 & 0.66 \\
\hline BBB & Bulgaria & 1.20 & 26.0 & 0.87 & AA & USA & 0.59 & 6.7 & 0.45 \\
\hline BBB & Colombia & 0.16 & 2.6 & 0.07 & A & Slovenia & 2.36 & 8.8 & 0.62 \\
\hline BBB & Croatia & 1.23 & 24.2 & 0.86 & A & Spain & 2.73 & 7.2 & 0.45 \\
\hline $\mathrm{BBB}$ & Iceland & 1.67 & 15.2 & 0.71 & $\mathrm{BBB}$ & Bahrain & 0.75 & 5.5 & 0.41 \\
\hline BBB & Italy & 1.41 & 13.1 & 0.64 & $\mathrm{BBB}$ & Ireland & 2.10 & 10.9 & 0.68 \\
\hline BBB & Mexico & 0.56 & 15.1 & 0.70 & BBB & Kazakhstan & 1.51 & 10.0 & 0.56 \\
\hline $\mathrm{BBB}$ & Panama & 0.31 & 9.1 & 0.46 & $\mathrm{BBB}$ & Lithuania & 1.11 & 12.8 & 0.73 \\
\hline BBB & Peru & 0.48 & 5.4 & 0.24 & $\mathrm{BBB}$ & Morocco & 0.23 & 6.7 & 0.53 \\
\hline $\mathrm{BBB}$ & Russia & 1.24 & 16.9 & 0.76 & $\mathrm{BB}$ & Costa Rica & 0.33 & 10.8 & 0.77 \\
\hline $\mathrm{BBB}$ & South Africa & 0.73 & 19.8 & 0.80 & $\mathrm{BB}$ & Cyprus & 2.95 & 30.6 & 0.99 \\
\hline BBB & Thailand & 0.55 & 27.5 & 0.89 & $\mathrm{BB}$ & El Salvador & 0.51 & 15.2 & 0.88 \\
\hline BB & Hungary & 1.08 & 23.4 & 0.85 & $\mathrm{BB}$ & Guatemala & -0.19 & -1.8 & 0.13 \\
\hline $\mathrm{BB}$ & Indonesia & 0.48 & 9.2 & 0.49 & $\mathrm{BB}$ & Latvia & 0.77 & 6.4 & 0.42 \\
\hline BB & Philippines & 0.06 & 0.9 & 0.01 & $\mathrm{BB}$ & Vietnam & 0.55 & 20.2 & 0.83 \\
\hline BB & Portugal & 2.79 & 22.6 & 0.84 & B & Argentina & 1.65 & 11.3 & 0.62 \\
\hline BB & Romania & 0.68 & 30.5 & 0.91 & B & Dominican & -0.12 & -0.7 & 0.07 \\
\hline $\mathrm{BB}$ & Turkey & 0.25 & 6.4 & 0.31 & B & Ecuador & 0.73 & 12.3 & 0.90 \\
\hline B & Ukraine & 0.67 & 17.5 & 0.77 & B & Egypt & 0.43 & 10.3 & 0.69 \\
\hline B & Venezuela & 1.03 & 6.3 & 0.30 & B & Lebanon & 0.15 & 6.0 & 0.42 \\
\hline CCC & Greece & 1.28 & 40.2 & 0.94 & B & Pakistan & 0.51 & 26.0 & 0.90 \\
\hline Average & AAA & 1.27 & 11.9 & 0.59 & Average & AAA & 1.33 & 10.2 & 0.65 \\
\hline Average & $\mathrm{AA}$ & 1.65 & 12.5 & 0.60 & Average & $\mathrm{AA}$ & 1.55 & 8.4 & 0.58 \\
\hline Average & A & 1.16 & 18.7 & 0.75 & Average & A & 2.54 & 8.0 & 0.54 \\
\hline Average & $\mathrm{BBB}$ & 0.86 & 15.2 & 0.61 & Average & BBB & 1.14 & 9.2 & 0.58 \\
\hline Average & $\mathrm{BB}$ & 0.89 & 15.5 & 0.57 & Average & $\mathrm{BB}$ & 0.82 & 13.6 & 0.67 \\
\hline Average & $\mathrm{B}$ & 0.85 & 11.9 & 0.54 & Average & B & 0.56 & 10.9 & 0.60 \\
\hline Overall & Mean & 1.08 & 15.8 & 0.63 & Overall & Mean & 1.19 & 10.3 & 0.61 \\
\hline Overall & SD & 0.66 & 8.7 & 0.25 & Overall & SD & 0.81 & 6.2 & 0.20 \\
\hline Overall & Min & 0.06 & 0.9 & 0.01 & Overall & Min & -0.19 & -1.8 & 0.07 \\
\hline Overall & Med & 1.04 & 15.2 & 0.71 & Overall & Med & 1.19 & 9.7 & 0.64 \\
\hline Overall & Max & 2.88 & 40.2 & 0.94 & Overall & Max & 2.95 & 30.6 & 0.99 \\
\hline
\end{tabular}




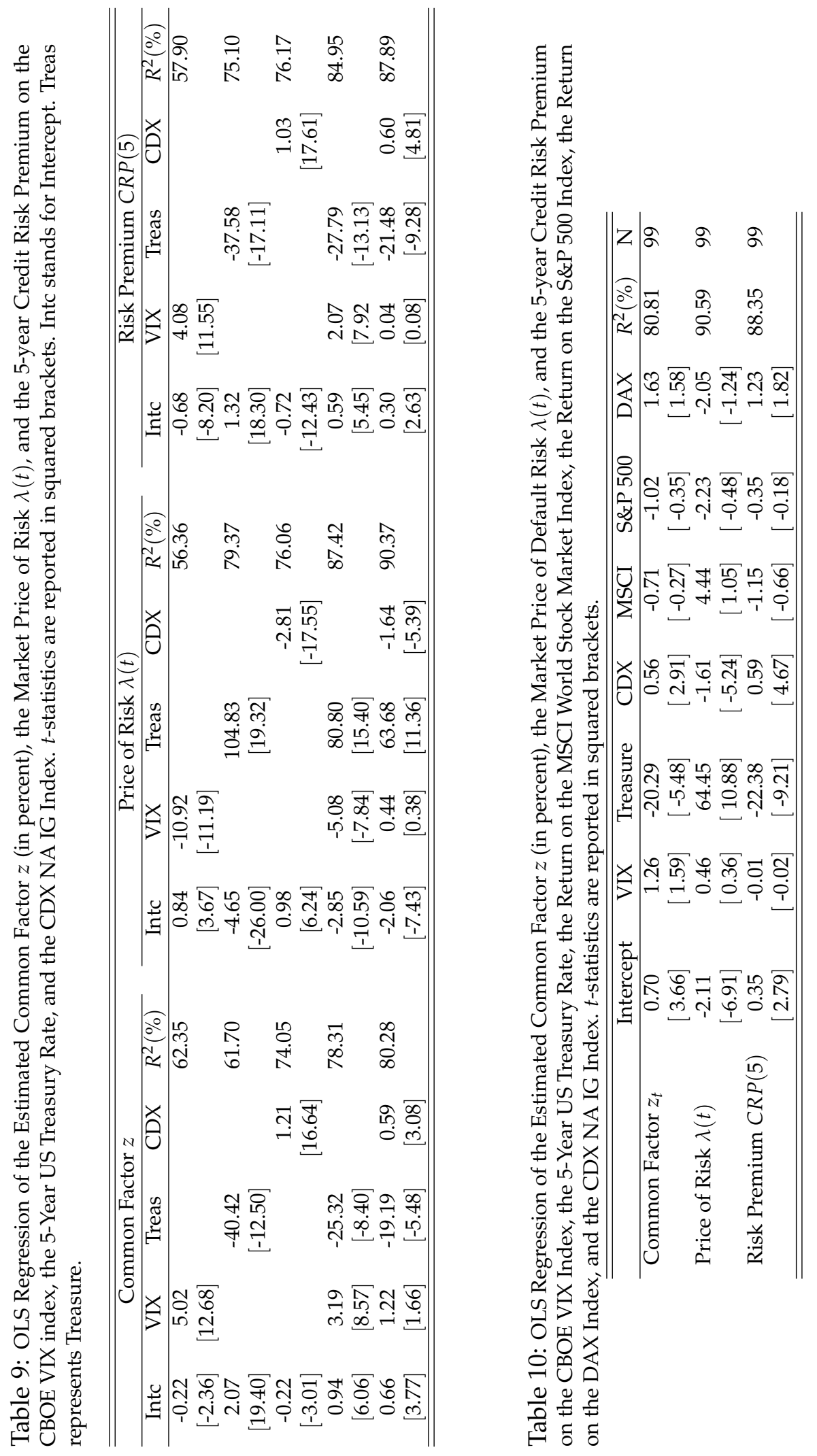



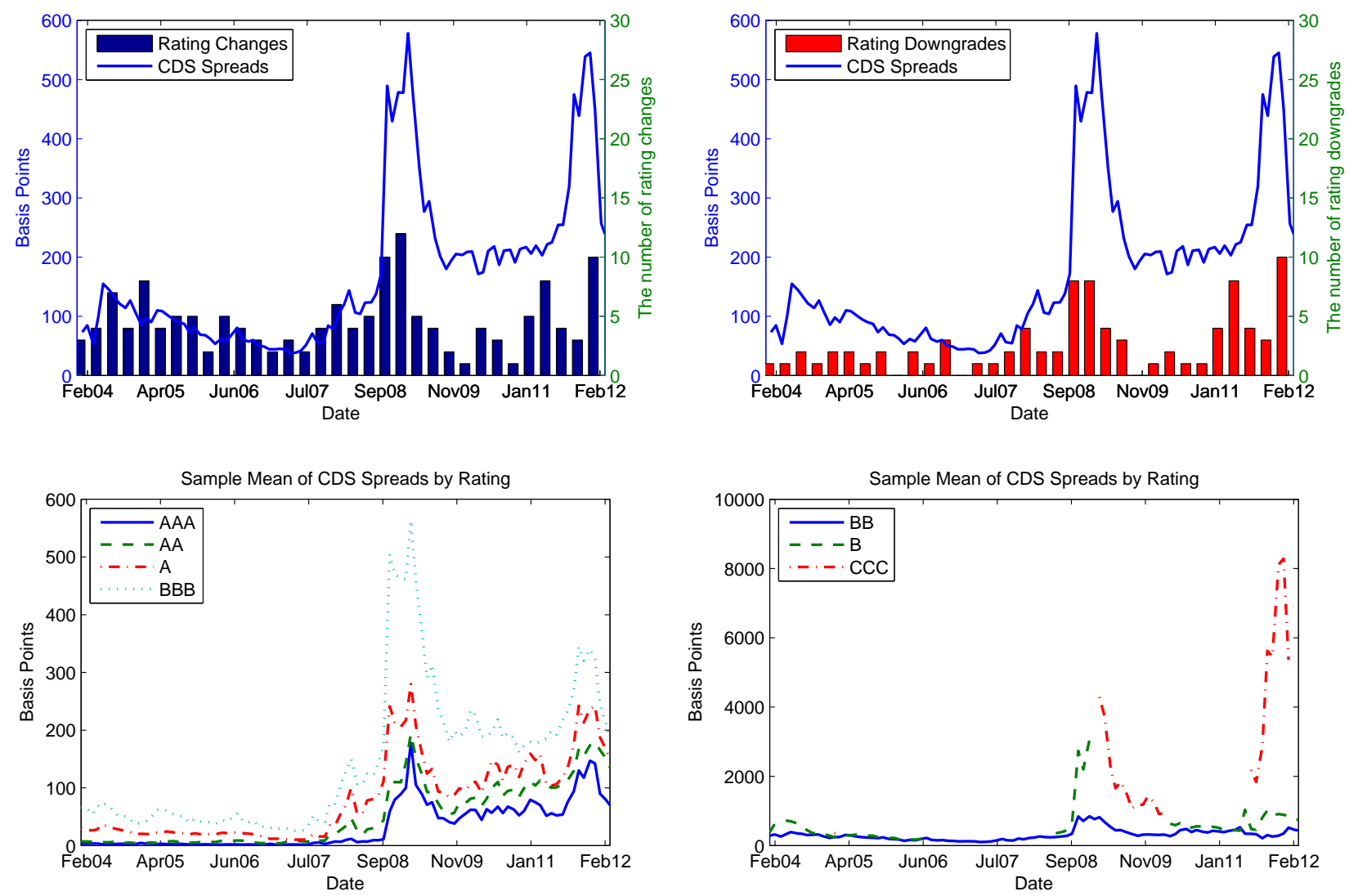

Figure 1: Top Left (Right) Panel: Time Series of 5-Year CDS Spreads Averaged Across Countries and Maturities and Quarterly Rating Changes (Downgrades) by One Notch or More. Numbers of rating changes here include those with minor changes (e.g., "+" and "-") within each broad rating category. Bottom Panels: Time Series of 5-Year CDS Spreads Averaged Across Countries at Seven Different Ratings. 

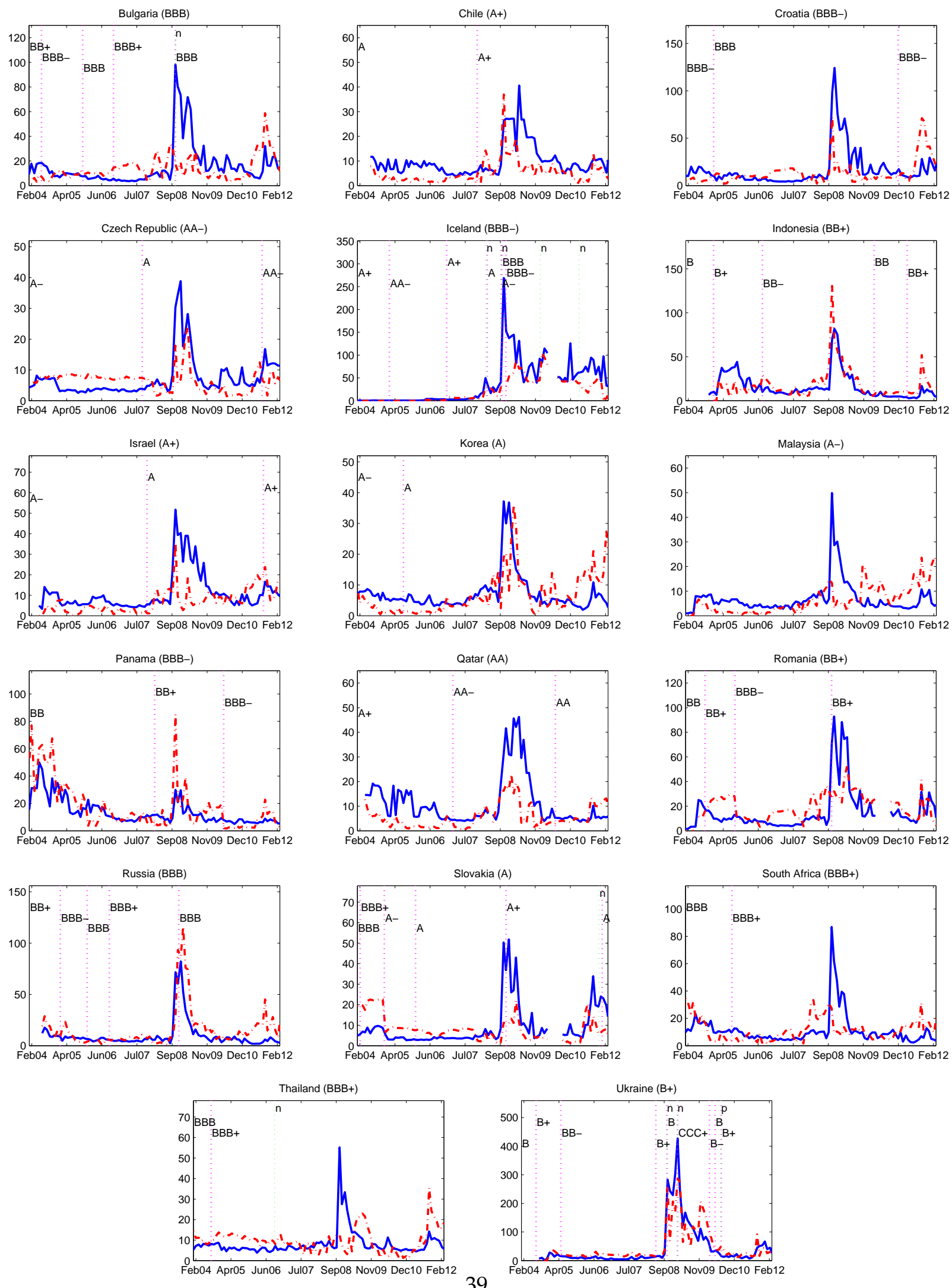

Figure 2: Time Series of Absolute Pricing Errors (dash-dot lines) and Bid-Ask Spreads (solid lines) Averaged Across Maturities for In-sample Non-Eurozone Countries with Low Pricing Errors. "SD" is for Selective Default, " $\mathrm{n}$ " is for negative Credit Watch, " $\mathrm{p}$ " is for positive Credit Watch. Vertical lines represent the dates of credit rating changes for each country. 

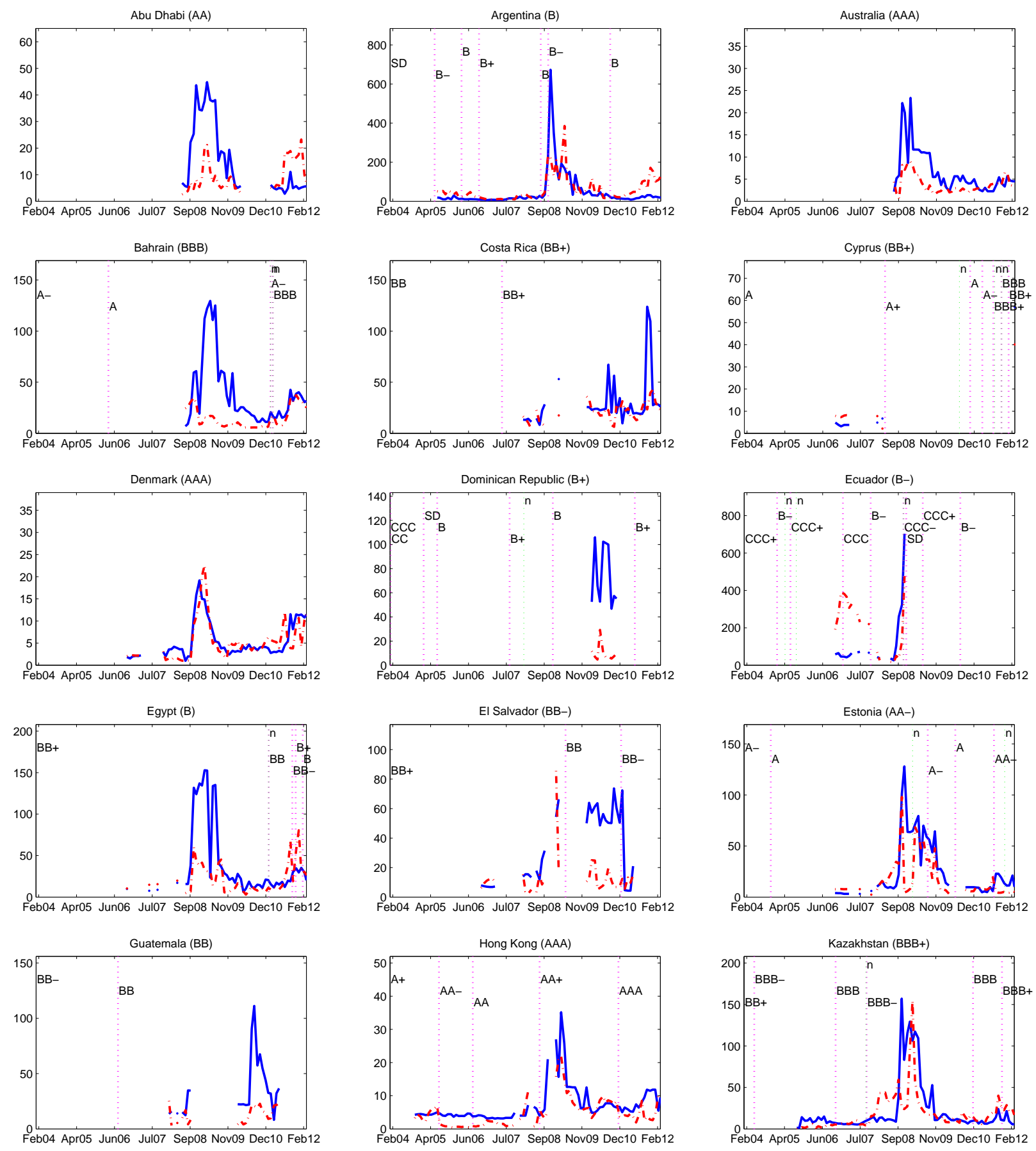

Figure 3: Time Series of Absolute Pricing Errors (dash-dot lines) and Bid-Ask Spreads (solid lines) Averaged Across Maturities for Out-of-Sample Non-Eurozone Countries. "SD" is for Selective Default, " $\mathrm{n}$ " is for negative Credit Watch, " $\mathrm{p}$ " is for positive Credit Watch. Vertical lines represent the dates of credit rating changes for each country. 

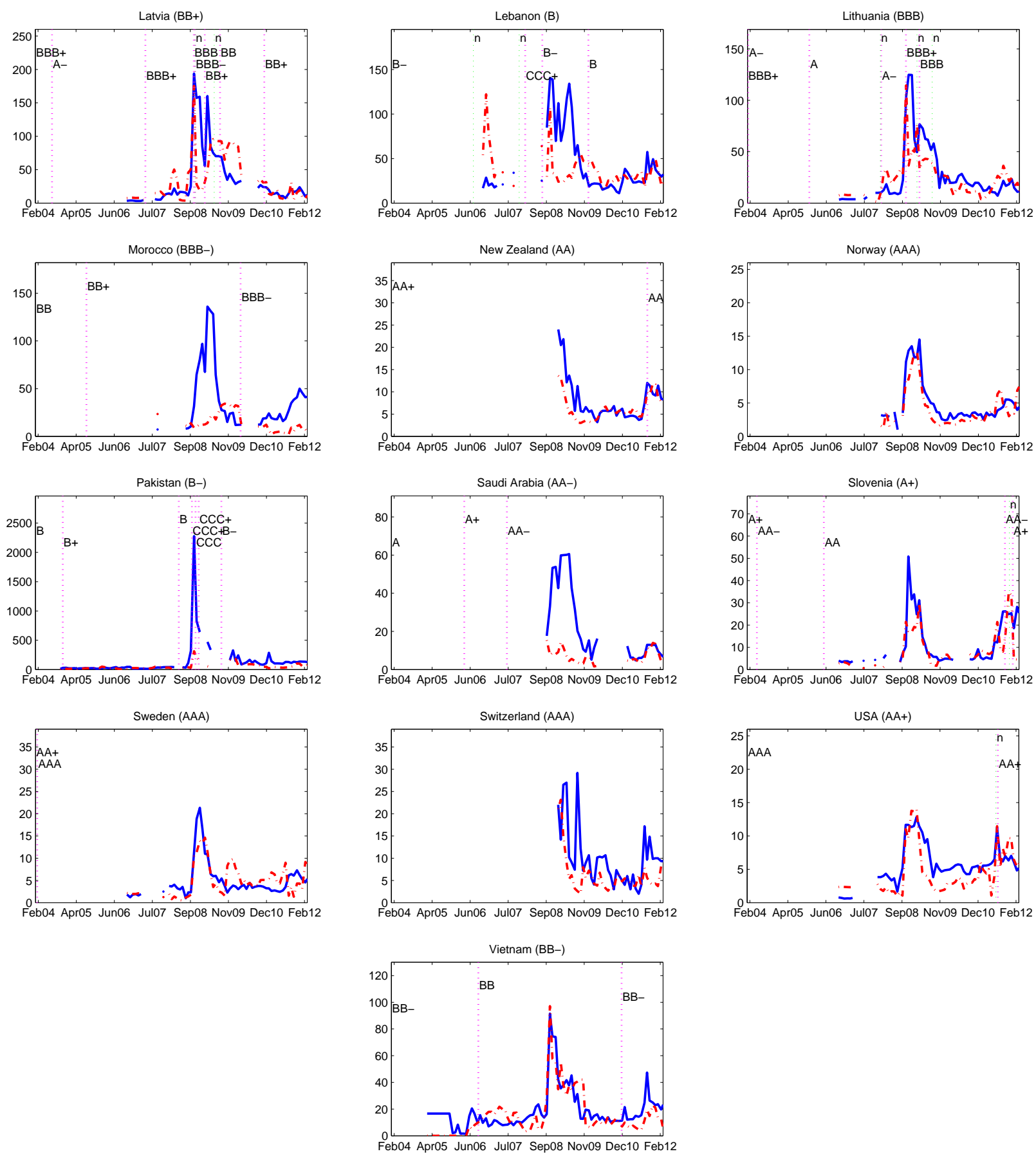

Figure 3: (Continued) 

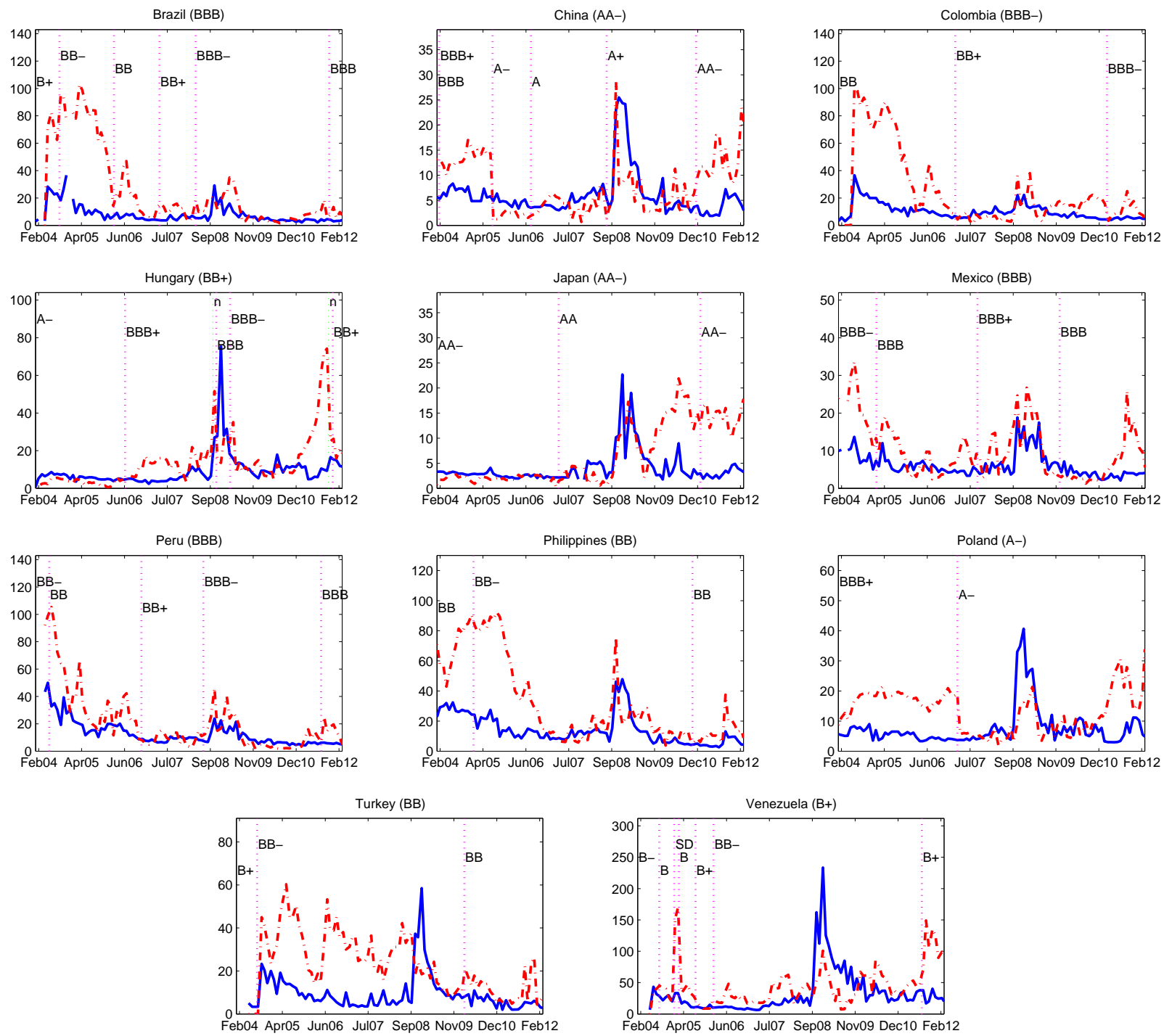

Figure 4: Time Series of Absolute Pricing Errors (dash-dot lines) and Bid-Ask Spreads (solid lines) Averaged Across Maturities for In-Sample Non-Eurozone Countries with High Pricing Errors. "SD" is for Selective Default, " $\mathrm{n}$ " is for negative Credit Watch, " $\mathrm{p}$ " is for positive Credit Watch. Vertical lines represent the dates of credit rating changes for each country. 

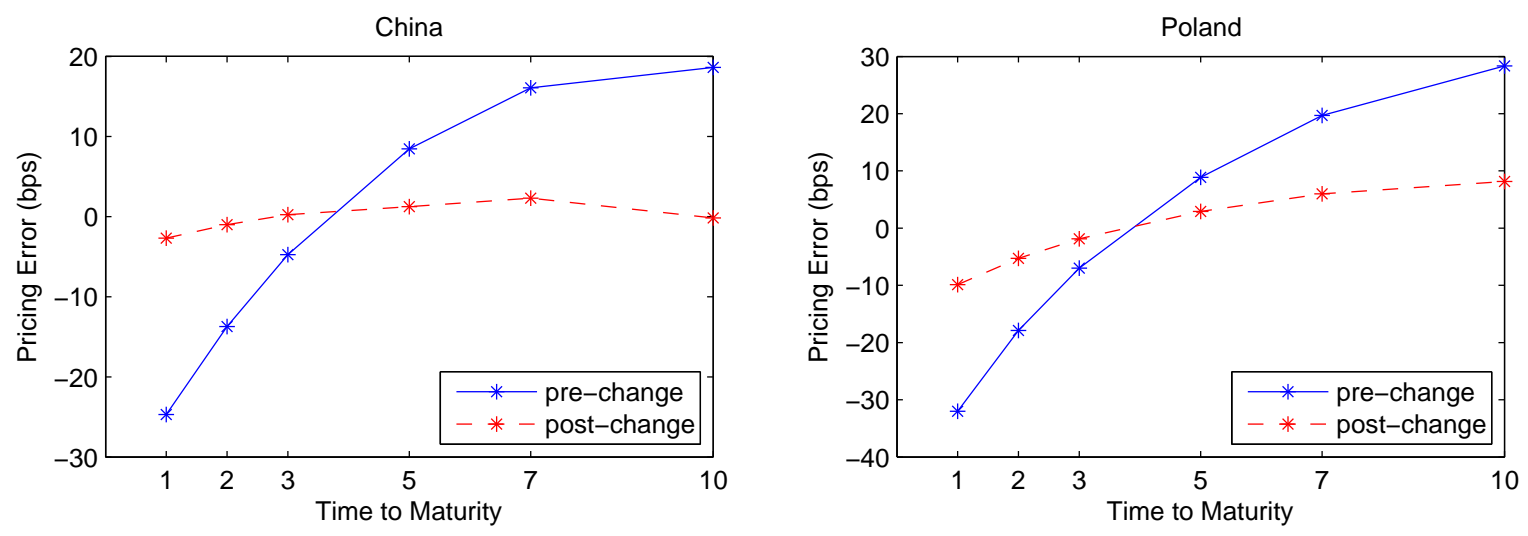

Figure 5: Changes in CDS Pricing Errors Across Maturities for China and Poland Around Rating Upgrades. China and Poland were upgraded to A- from BBB+ on July 20, 2005 and March 29, 2007, respectively.
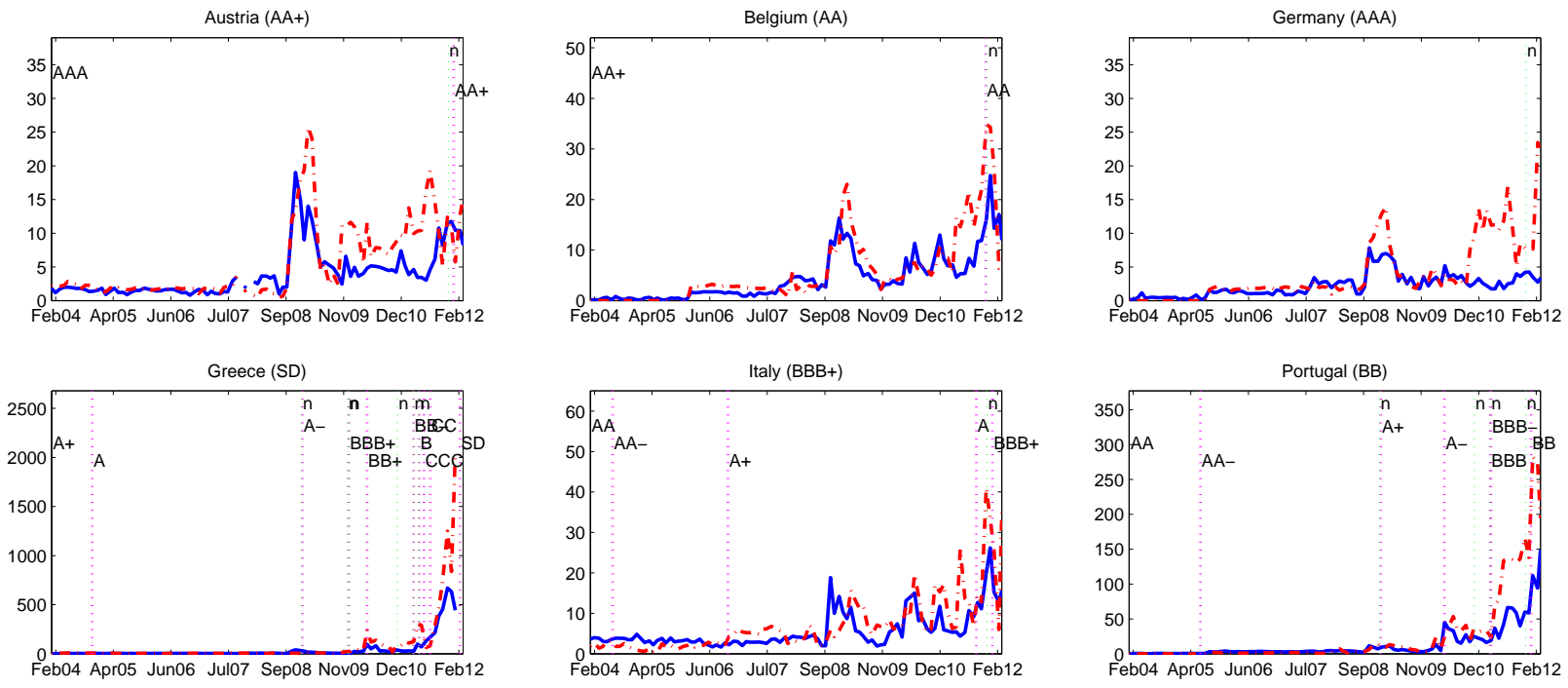

Figure 6: Time Series of Absolute Pricing Errors (dash-dot lines) and Bid-Ask Spreads (solid lines) Averaged Across Maturities for In-Sample Eurozone Countries. "SD" is for Selective Default, " $\mathrm{n}$ " is for negative Credit Watch, " $\mathrm{p}$ " is for positive Credit Watch. Vertical lines represent the dates of credit rating changes for each country. 

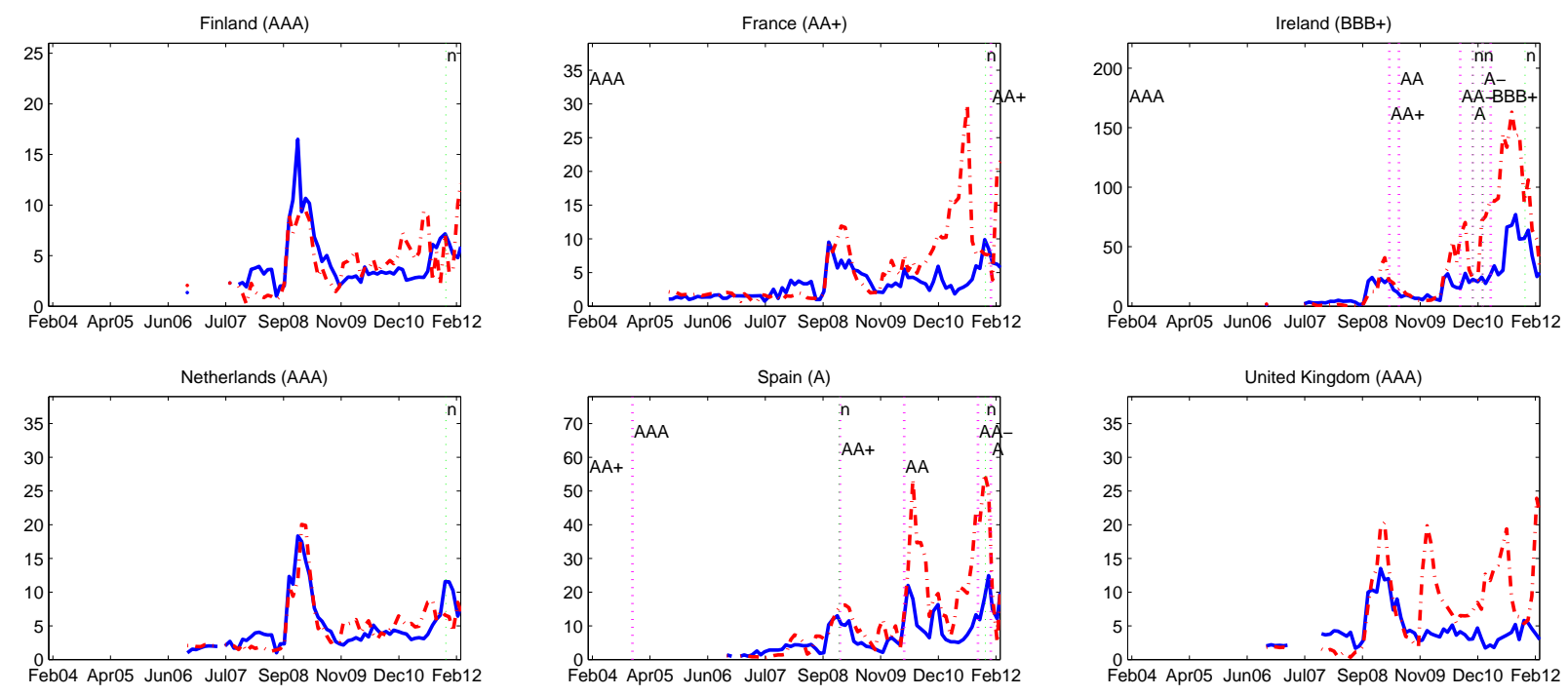

Figure 7: Time Series of Absolute Pricing Errors (dash-dot lines) and Bid-Ask Spreads (solid lines) Averaged Across Maturities for Out-of-Sample Eurozone Countries. "SD" is for Selective Default, " $\mathrm{n}$ " is for negative Credit Watch, " $\mathrm{p}$ " is for positive Credit Watch. Vertical lines represent the dates of credit rating changes for each country. 

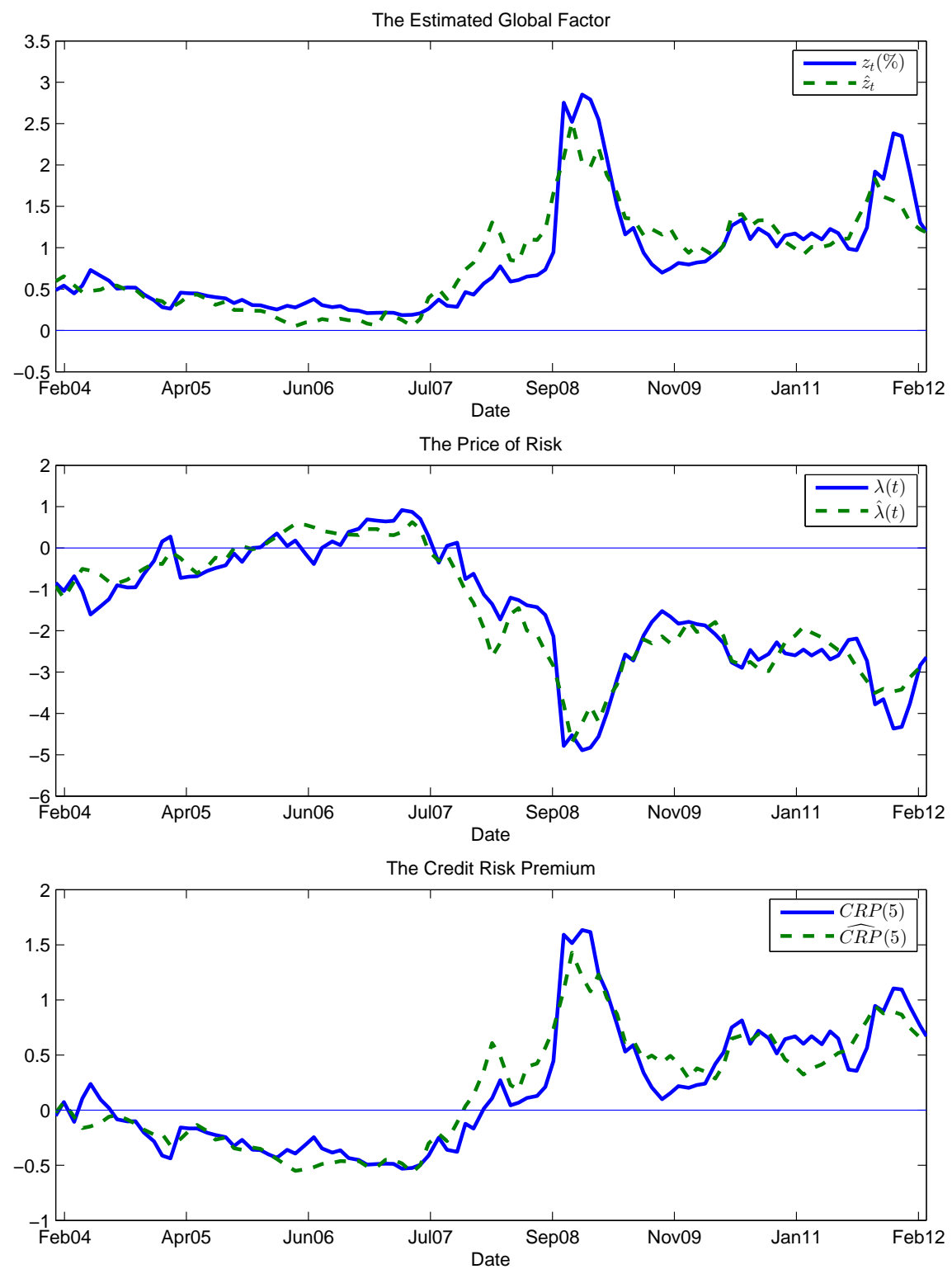

Figure 8: Time Series of the Estimated $z_{t}$, the Price of Risk $\lambda(t)$, and the Average 5-Year Credit Risk Premium. The average 5 -year CRP is computed by (16) for 5-year CDS contracts over all countries. The hatted time series are the respective predicted values based on OLS regressions (with 3 explanatory variables) in Table 9. 

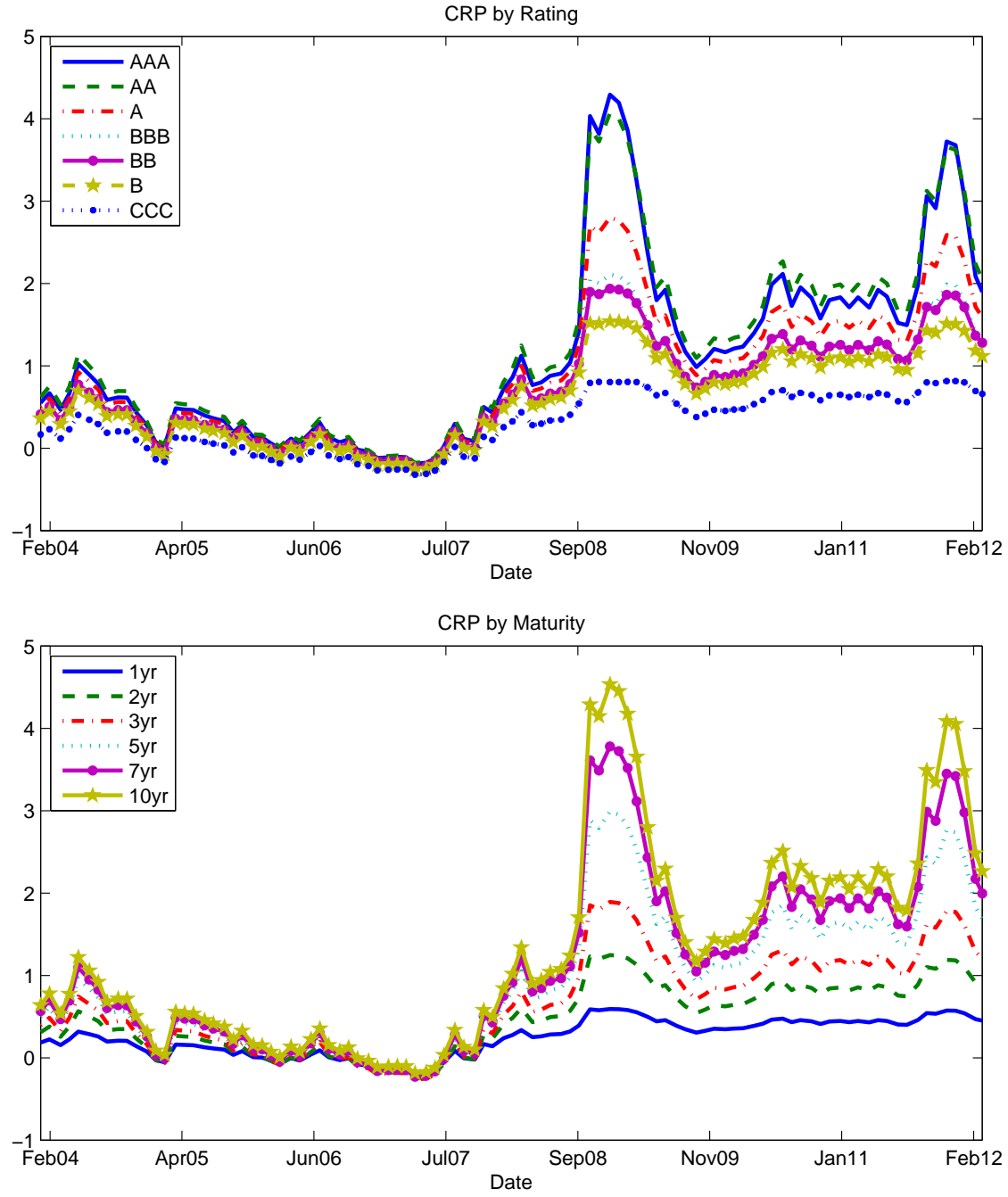

Figure 9: Average Credit Risk Premium for Different Ratings and Maturities. The average CRP for each rating is computed by (16) over all 6 maturities (1y, 2y, 3y, 5y, 7y, 10y), and the average CRP for each maturity is computed by (16) over all 7 ratings. All calculations are based on the estimation of Model I reported in Table 3 with zero country-specific factor. 